\title{
REVIEW
}

Open Access

\section{An overview of recent progress in modern synthetic approach-combinatorial synthesis}

Chandravadivelu Gopi ${ }^{*}$, Gudapati Krupamai ${ }^{1}$, Chitikina Satya Sri ${ }^{1}$ and Magharla Dasaratha Dhanaraju ${ }^{2}$

\begin{abstract}
Background: In recent times, a powerful tool of combinatorial synthesis has been used for the preparation of large chemical entities through a small set up of reactions between different building blocks using solidphase and solution-phase techniques. This method reduced the time and cost of the drug discovery process substantially.

Main text: Thousands of compounds are synthesised in a few reactions through combinatorial synthesis instead of getting a few compounds in the traditional method. This method also helps to identify chemical lead of the compounds and optimise them through the biological screening using a high-throughput method. There is no review concerning the recent research finding of combinatorial synthesis. Hence, an attempt had been made on the latest research findings (2002-2020) of newly synthesised compounds using combinatorial synthesis and their biological activities.
\end{abstract}

Conclusion: To the best of our knowledge, the current review has completely analysed the importance of combinatorial synthesis and furnished an overview of solid-phase and solution-phase techniques as well as helped mankind by improving higher productivity at low cost, lead identification and optimization and preventing environmental pollution.

Keywords: Combinatorial synthesis, Solid phase, Solution phase, Higher productivity

\footnotetext{
* Correspondence: gopi@giet.ac.in

${ }^{1}$ Department of pharmaceutical chemistry, GIET School of Pharmacy, NH-16,

Rajahmundry, Andhra Pradesh 533296, India

Full list of author information is available at the end of the article
}

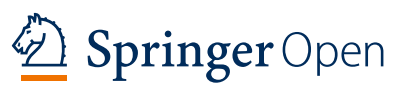

(c) The Author(s). 2020 Open Access This article is licensed under a Creative Commons Attribution 4.0 International License, which permits use, sharing, adaptation, distribution and reproduction in any medium or format, as long as you give appropriate credit to the original author(s) and the source, provide a link to the Creative Commons licence, and indicate if changes were made. The images or other third party material in this article are included in the article's Creative Commons licence, unless indicated otherwise in a credit line to the material. If material is not included in the article's Creative Commons licence and your intended use is not permitted by statutory regulation or exceeds the permitted use, you will need to obtain permission directly from the copyright holder. To view a copy of this licence, visit http://creativecommons.org/licenses/by/4.0/. 


\section{Background}

The traditional method of drug synthesis is a useful technique but a time-consuming and expensive process [1, 2]. Therefore, pharmaceutical industries around the world are looking at the alternative method of synthesis of new drug molecules. Combinatorial synthesis is one of the novel methods to reduce the time and expenses and gets a large number of compounds in a short period instead of getting a few compounds in the traditional method of synthesis (Fig. 1) [3, 4]. It is a novel technique in which a large number of structurally distinct molecules can be synthesised simultaneously and finding out their pharmacological activities using a highthroughput screening method [5-7]. It has been used by industries in 1990, but the basic concept of solidphase peptide synthesis had been proclaimed by Merrifield in 1963 [8]. Since, solid-phase synthesis has been developed as an efficient method of techniques for the preparation of numerous peptides, oligonucleotides, organometallic, small proteins, nonoligomeric organic molecules, inorganic molecules and polymer chemistry (Fig. 2) [9-11]. The key to combinatorial chemistry is that a large range of analogues has been synthesised using the same reaction conditions in the same reaction vessels [12]. Here, the number of compounds produced far exceeds the number of chemical steps taken [13]. In this way, the pharmaceutical industries can synthesise

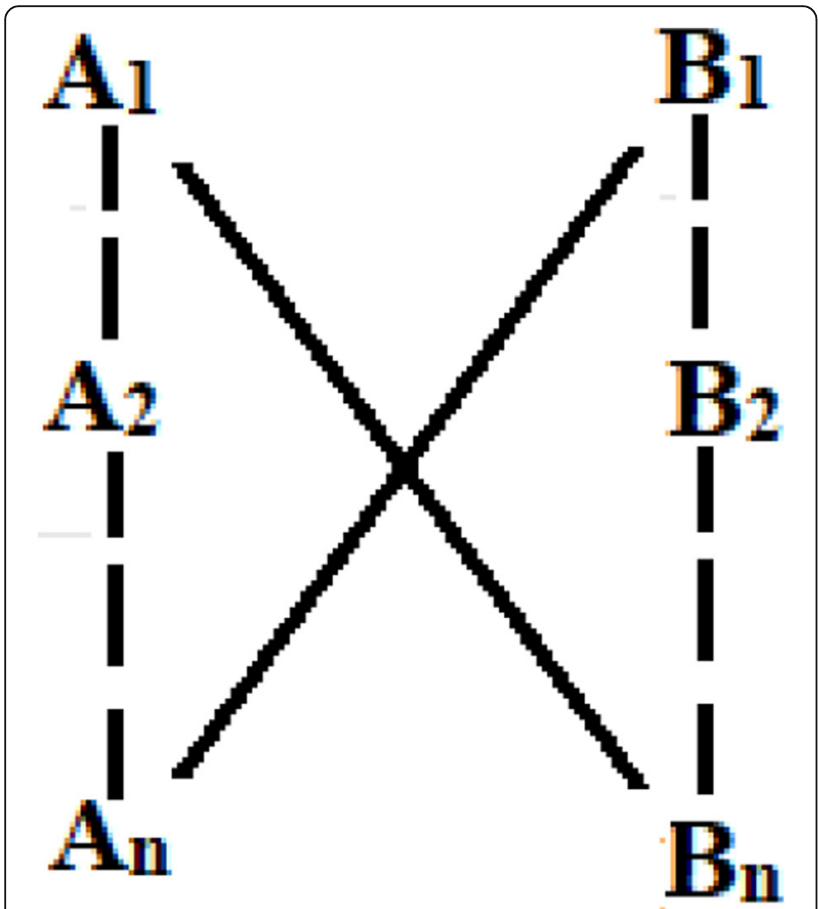

Fig. 1 Combinatorial synthesis thousands of compounds in a few reactions instead of getting a few compounds by the traditional method [14]. During the literature survey, we have found some of the researchers exclusively used combinatorial synthesis for the preparation of a new drug molecule using solid-phase and solution-phase techniques. These compounds were achieved in a short period. But, there is no review concerning recent research discoveries of novel drug molecules using combinatorial synthesis. Hence, this review provides complete knowledge about the recently synthesised drug molecules using combinatorial synthesis and their biological activities using a highthroughput screening method.

\section{Main text}

Combinatorial synthesis has two phases such as preparing a combinatorial library or an array and screening of biological activities of the library [15]. These can be achieved by using solid-phase and solution-phase synthesis techniques [16, 17]. Solidphase synthesis is carried out with the aid of resin beads that are treated as a base for building blocks and linker [18, 19]. The selection of the bead depends on the type of reactions carried out on the surface of the bead [20]. It is allowing the reaction of the substrate with the different reagents to achieve products. Chemical and radio frequency tagging has been used often for the synthesis of the specific compounds in a solid-phase synthesis which act as a code for the individual step of the synthesis and separated them at the end of the synthesis from bead and products [21]. The excess reagent and product have been easily removed from the resin bead by washing with suitable solvents [22]. Solution-phase synthesis performs the chemical reaction preferably in a solution using a well-ordered set of reacting vessels to attain combinatorial libraries [23]. This method has been restricted to synthesise the libraries bearing two to three steps.

\subsection{Solid-phase synthesis}

Solid-phase synthesis has shown several advantages including the easy process of isolation of products which can be obtained by filtering, ensures complete conversion of a product from the substrates, toxic and safe handling of explosive reagent etc. [24-26]. The essential requirements of solid-phase synthesis are cross-linked insoluble polymer support, linker, substrate, reagent and chemical protecting groups [27]. It has been carried out by using either parallel or split and mix procedures using insoluble polymer support [28]. Geysen had reported a recent development of an encoding strategy in which molecular 


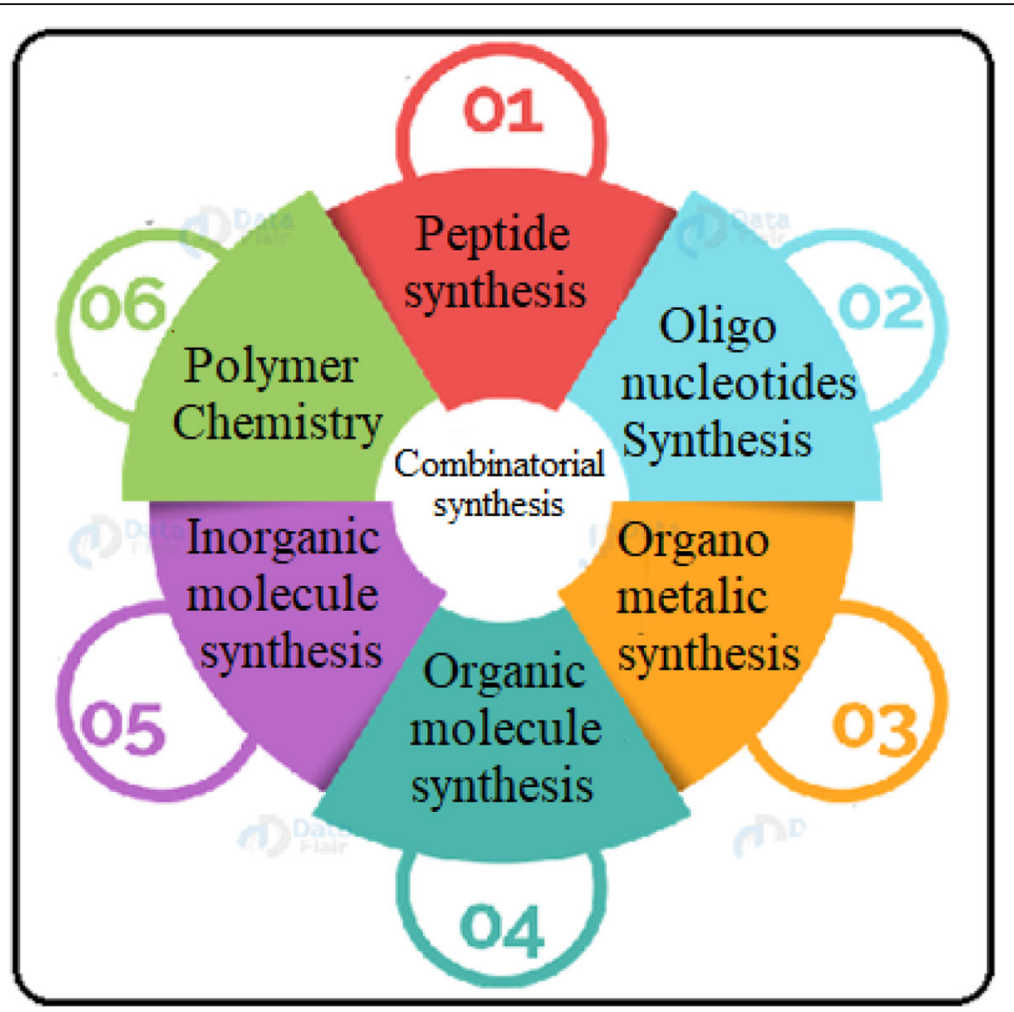

Fig. 2 Application of combinatorial synthesis

tags are attached to beads or linker groups used in solid-phase synthesis at the Coronado conference. It can be used to carry out the appropriate chemical reactions between the building blocks in a proper sequence [29-31] (Fig 3).

\subsubsection{Synthesis of heterocyclic compounds}

Batra et al. [32] described the synthesis of isoxazolebased libraries such as 3-substituted phenyl-5isoxazolecarboxaldehydes through solid-phase synthesis. Three highly functionalised isoxazole-based libraries comprising thirty-two, ninety-six and fortyfive were synthesised in the parallel method using the Baylis Hilman reaction, Michael addition, reductive amination and alkylation reactions. Out of these synthesised compounds screened for in vivo antithrombin activity, 2-chlorophenyl substituted compounds showed significant antithrombin activity and their potency has been compared with aspirin (Schemes 1 and 2).

Portilla et al. [17] carried out a novel method of synthesis of 1-pyrazol-3-ylbenzimidazoles from 5(3)amino-3(5)-substituted-1H-pyrazole and 4-fluoro-3nitrobenzoate derivatives by using solid-phase and solution-phase syntheses. It is a nucleophilic aromatic substitution reaction that takes place between the activated fluorine and exocyclic amino group of pyrazole ring which convert the raw materials into title compounds with high yield. The method is very useful to generate the number of libraries of heteroaryl benzimidazoles (Schemes 3 and 4).

Murru et al. [33] synthesised oxazol-thiazole bis heterocyclic compounds with excellent yields and high purity by using solid-phase and solution-phase syntheses. Here, oxazole containing heterocyclic compounds were obtained from serine methyl ester and amino acid through coupling and cyclodehydration in the presence of Fmoc-NCS and $\alpha$ haloketones, whereas thiazole compounds were obtained from $\alpha$-haloketones and Fmoc-isothiocyanate (Schemes 5 and 6).

\subsubsection{Synthesis of peptide and proteins}

On the other hand, a group of researchers led by Drew et al. [34] have been focused and developed a wild-type form of the $S^{21}$ pinholin, $S^{21} 68$ and negative-dominant mutant form $S^{21}$ IRS using solidphase peptide synthesis and studied through biophysics techniques. Later, the duo pinholins have been labelled with nitroxide and successfully incorporated into bicelles and multilamellar vesicles which are membrane mimetic systems. These compounds characterised by NMR spectroscopic data indicated a 


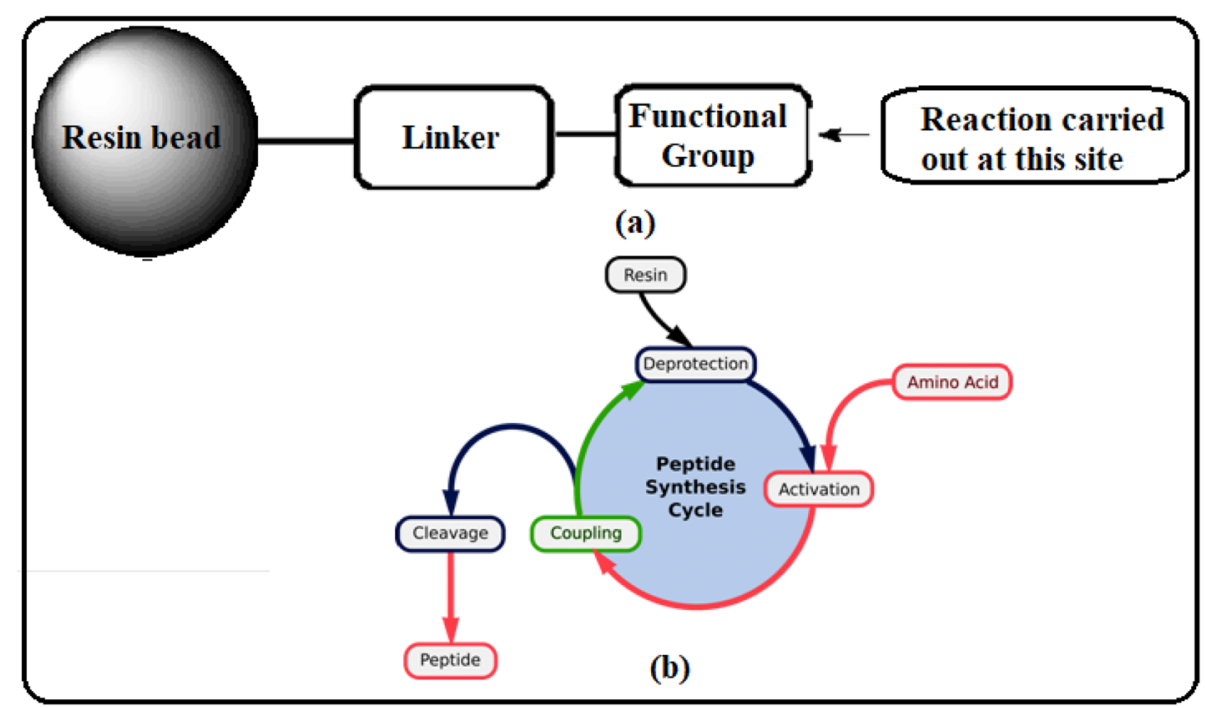

Fig. 3 a A schematic representation of solid-phase synthesis. b Peptide synthesis usingSolid-phase synthesis

strong interaction of pinholes with the membrane headgroups.

Sun et al. [35] reported a peptide disulphide bond mimics on the incorporation of diaminodiacids through solid-phase synthesis. It is the most effective method for the synthesis of peptide disulphide bond mimics containing a five-atom thioether (C-C-S-C-C). In this work, oxytocin containing a new disulphide bond mimic was achieved. The current diaminodiacid method can do four atom-linked mimics and does not fully meet the activity of the optimization requirement (Schemes 7, 8, 9 and 10).

Blanc et al. [36] found that $\alpha$-amanitin a potent inhibitor of RNA Polymerase II and synthesised two amanitin derivatives using one bead and one compound using solid-phase synthesis. The amatoxin family made up of several rigid bicyclic octapeptides with transannular tryptathionine crosslink had been prepared by Savige-Fontana tryptathionylation of 3ahydropyrrolo[2,3-b]indoline in neat TFA. Later, cellular uptake and toxic nature of these derivatives were evaluated (Schemes 11, 12, 13, 14 and 15).

A naked-eye detection of the free amino group has been tested by Rajavenkatesh et al. [37] using solidphase peptide synthesis. It is a catalytic cyclisation technique of 2-(2-oxo-2H-acenaphthylene-1-ylidene)malononitrile and oxidative substitution of aryl moiety by free amine group existing in $N$-terminal position of the peptide chain. The above-mentioned reaction is taking place in situ, does not require any heating process and allows $\mathrm{N}$-terminal modification of peptides suitable for imaging specific cells (Scheme 16).

Liu et al. [38] prepared a genetically encoded amino acid called selenocysteine (sec) by solid-phase peptide synthesis. It is used to expand the reactivity of enzymes and to modify folding, has high stability and conjugation and facilitates the reactivity. He emphasised a recent advancement of complicated selenoproteins including novel uses of protecting groups and

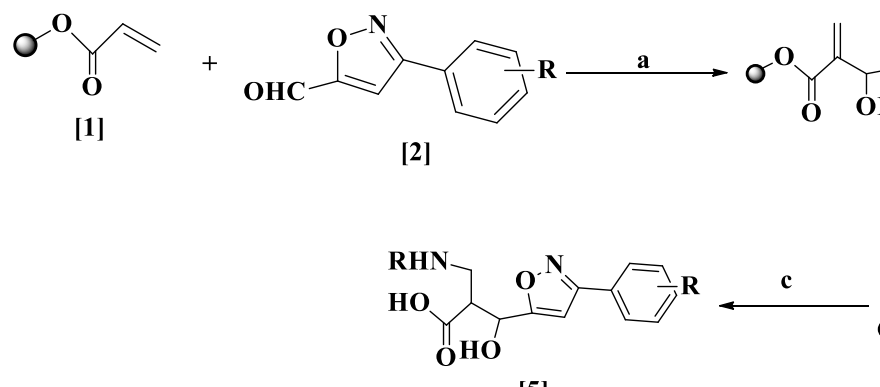

[5]

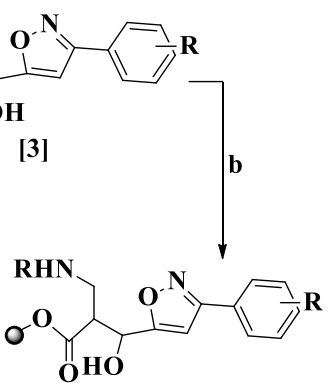

[4]

Scheme 1 Synthesis of 3-substituted phenyl-5-isoxazolecarboxaldehydes by Michael addition 


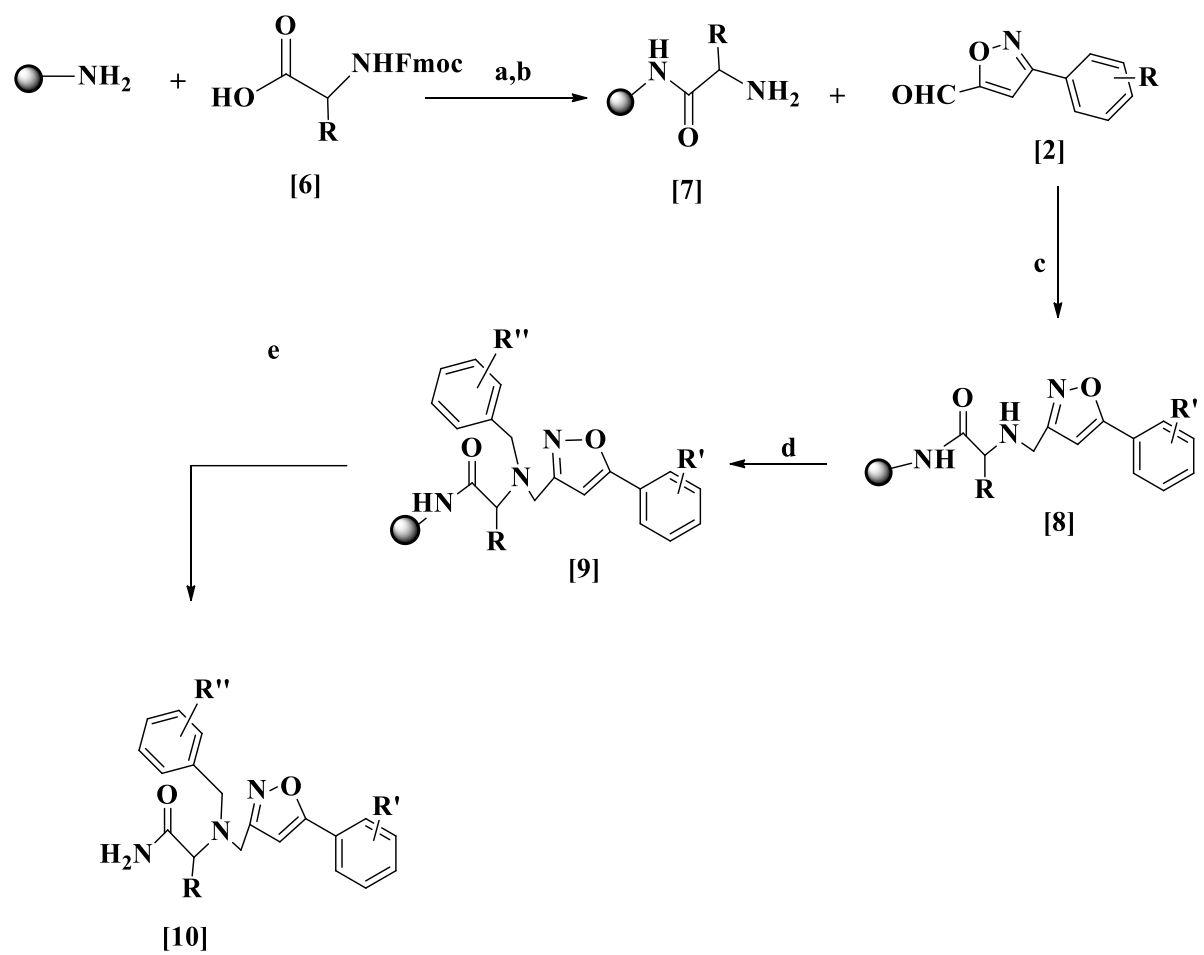

Scheme 2 Synthesis of 3-substituted phenyl-5-isoxazolecarboxaldehydes by reductive amination and alkylation reactions

rapid selenoester-driven chemical ligations and expressed versatile protein ligations (Schemes 17 and 18).

Monaim et al. [39] found a novel method of synthesis of cyclic homodetic peptides by cyclic head to side-chain and cyclative cleavages using FmocMeDbz-resin. It has a cyclic structure formed through amide bonds and is used exclusively in medicinal chemistry. In contrast, for the synthesis of the head to tail counterpart, the cyclative cleavage should be done in the presence of thiophenol (Scheme 19).

Ng-Choli et al. [40] described a new methodology of synthesis of biaryl bicyclic peptides bearing PhePhe, Phe-Tyr or Tyr-Tyr motif through solid-phase synthesis. These compounds were achieved in two steps. The initial step involves the cyclisation of halo and boronoamino acids through microwave-assisted Suzuki-Miyaura cross-coupling. In the second step, biaryl monocyclic peptidyl resin undergoes macrolactamization which leads to the biaryl bicyclic peptide (Schemes 20, 21, 22 and 23).

Shan et al. [41] found the disadvantage of the chemical and enzymatic method of synthesis of dipeptides such as toxic reagents had been used for the synthesis, less yield and least purity of the products. Therefore, he identified a novel method of preparation of dipeptide through solid-phase enzymatic synthesis (SPEPS). In this study, a tyrosine-alanine dipeptide (Tye-Ala) had been synthesised at the end of the third step in the presence of recombinant carboxypeptidase $\mathrm{Y}$ (CPY). It includes a $\mathrm{N}$-protected acyl donor covalently linked to the resin followed by the formation of a peptide bond between the acyl donor and nucleophile and removes the dipeptides from solid resin after cleavage. Finally, the synthesised compounds were screened for antioxidant activity by using the ABTS method. The result reveals that the synthesised dipeptide had shown superior antioxidant activity compared with glutathione (Scheme 24).

Ng-Choli et al. [42] synthesised biaryl cyclic peptides bearing His-Phe linkage through a feasible method of solid-phase synthesis strategy. The formation of the above product happened by linking a linear peptidyl resin with 5-bromohistidine and 4boronophenylalanine and carried out the cyclisation process between the imidazole of histidine and the phenyl group of phenylalanine through microwaveassisted Suzuki-Miyaura cross-coupling reaction. The method could be the useful one for the synthesis of biaryl cyclic peptides bearing histidine and phenylalanine linked at the $\mathrm{N}$ - and C-terminus of peptidyl resin (Schemes 25, 26, 27 and 28).

Li et al. [43] reported a novel method of synthesis of naturally occurring cyclic proline-enriched 

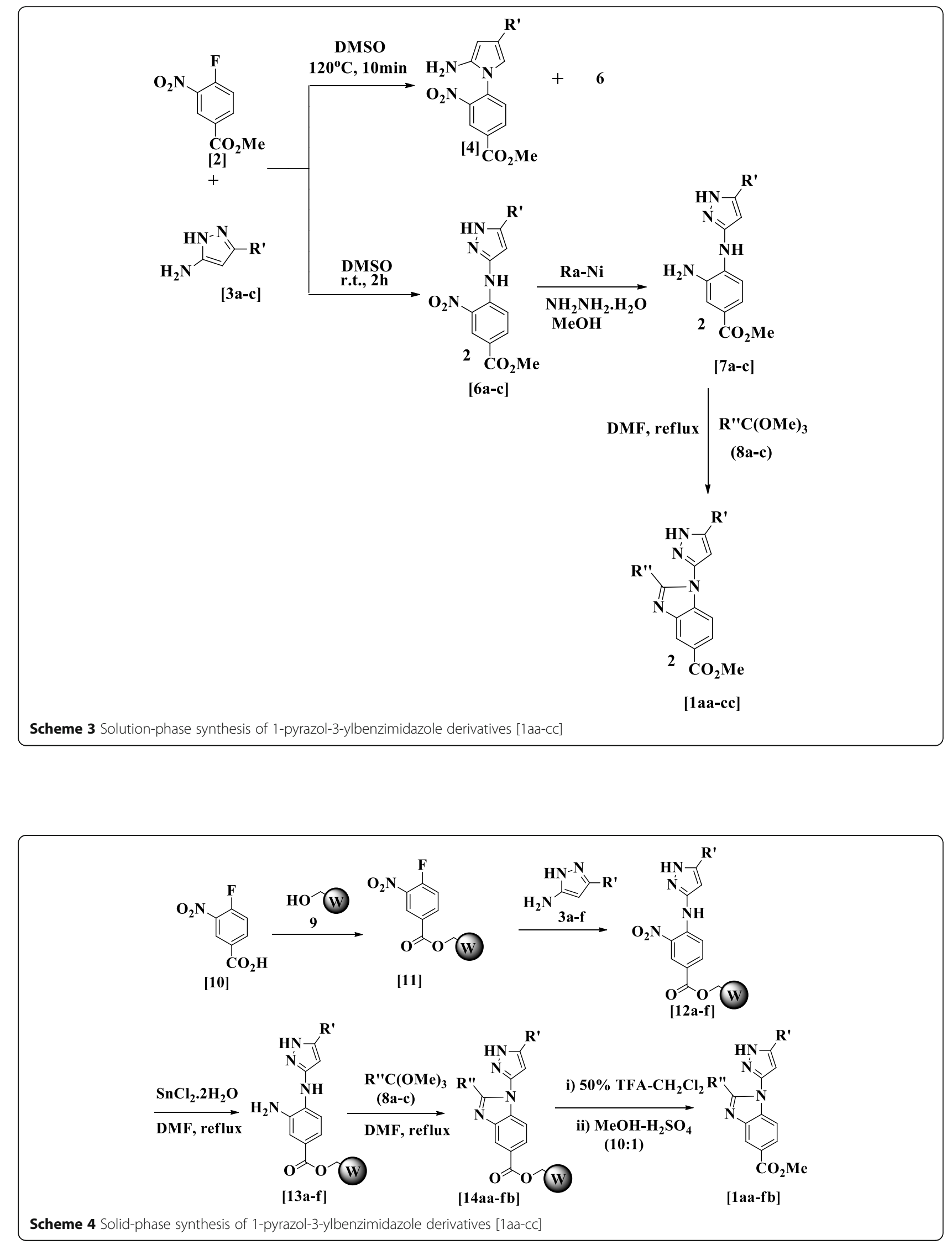
<smiles>[R]C(NC(=O)c1ccccc1)C(=O)O</smiles>

[1] $\left\{\begin{array}{l}\text { 1a-Leu } \\ 1 \text { b-Pro } \\ 1 \text { c-Val } \\ \text { 1d-Phe } \\ \text { 1e-Tyr(z-2-Br) }\end{array}\right\}$<smiles>[R]C(NCBr)c1nc(C(=O)O)co1</smiles>

[4] (i)<smiles>[R]C(NC([B])Br)C(=O)NC(CO)C(=O)OC</smiles>

[2]

(ii, iii)<smiles>[R]C(NCCCCc1ccccc1)c1nc(C(=O)OC)co1</smiles>

[3]

Scheme 5 Biomimetic synthesis of non-natural oxazole amino acid building blocks starting from amino acids and serine methyl ester<smiles>[R]C(N)c1nc(C(=O)O)co1</smiles>

[4]<smiles>C#CO</smiles><smiles>[R]C(N)c1nc(C(=[Se])NOC)co1</smiles>

[5]

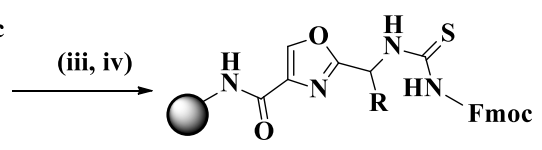

[6]<smiles>[R]c1nc(NC(N)=O)cs1</smiles>
$\mathrm{R}^{\mathrm{O}} \stackrel{\mathrm{N}}{\mathrm{X}} \mathrm{(v}^{\mathrm{v}, \mathrm{vi})}$<smiles>[Y7]c1csc(NC([R])c2nc(C(=O)NO)co2)n1</smiles>

[7]

Scheme 6 Solid-phase parallel synthesis of oxazol-thiazole bis-heterocycles $\left(5 R \times 4 R^{\prime}=20 R^{\prime}\right)$ via Hantzsch cyclisation starting from resin-bound oxazole amino acids<smiles>NC(CCO)C(=O)O</smiles>

Homoserine

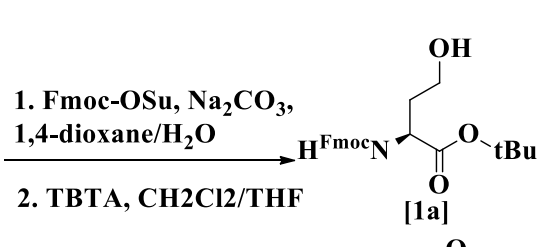

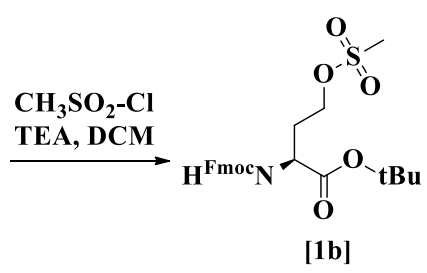

$\underset{\mathrm{K}_{2} \mathrm{CO}_{3}, \mathrm{DMF}}{\mathrm{CH}_{3} \mathrm{CO} \text {, }}$<smiles>[CH]CC(CCSC(C)=O)C(=O)OCC</smiles>

[1c]

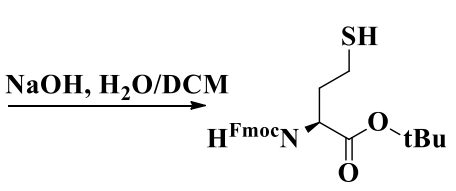

[1]

Scheme 7 The synthetic route of compound [1] 


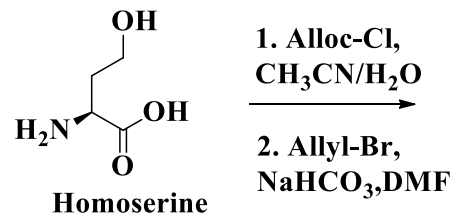

Homoserine

\section{$\mathrm{CH}_{3} \mathrm{CN} / \mathrm{H}_{2} \mathrm{O}$ \\ $\mathrm{NaHCO}_{3}, \mathrm{DMF}$}

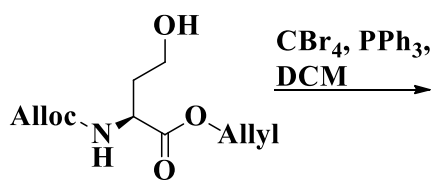

[2a]

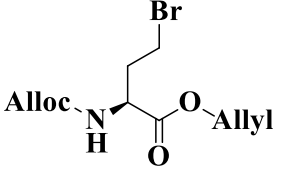

[2]

Scheme 8 The synthetic route of compound [2]

octapeptide phakellistatin 15 from marine sponge using solid/solution-phase synthesis. It required two steps of synthetic strategy to get the title compound. The linear octapeptide was assembled by Fmoc chemistry on 2-chlorotrityl chloride resin and cleaved off resin with acetic acid/dichloromethane/ trifluoroethanol. Finally, the synthesised compounds were purified and characterised by RP-HPLC system, HR-QTOF-MS, ${ }^{1} \mathrm{H}-\mathrm{NMR}$ and ${ }^{13} \mathrm{C}-\mathrm{NMR}$ (Scheme 29).

Jad et al. [44] described a novel method of synthesis of peptide through solid-phase synthesis using 2methyl tetrahydrofuran, ethyl acetate and isopropyl alcohol. These are called green solvents which eliminate the usage of $\mathrm{N}, \mathrm{N}$-dimethylformamide, $\mathrm{N}$ methyl-2-pyrrolidone and dichloromethane for deprotecting, washing and coupling process in the organic compound synthesis. The later solvents are creating toxic and hazardous nature to the environment (Scheme 30).

\subsubsection{Synthesis of organic compounds}

Meschaninova et al. [45] stated a novel synthesis of oligonucleotide conjugates through solid-phase synthesis based on the interaction of free 5-hydroxyl oligonucleotides and amino-containing ligands such as closo-dodecaborate, oestrone, cholesterol and alphatocopherol. Initially, functionalization of 5-hydroxyl oligonucleotides catalysed by $\mathrm{N}, \mathrm{N}$-disuccinimidyl carbonate followed by interaction with an amino group-containing ligand which led to the formation of a wide range of oligonucleotide conjugates such as closo-dodecaborate, lipophilic residues, aliphatic diamines, pyrene, short peptide and propargylamine. These compounds were characterised by ${ }^{1} \mathrm{H}-\mathrm{NMR}$, mass spectrometry and RP HPLC analyses (Schemes 31, 32 and 33).

Yang et al. [46] established green and rapid microwave-assisted solid-phase synthesis of fluorescent carbon nanoparticles (FCNP). This titled compound has shown excellent chemical stability and biocompatibility and can be fabricated in a short period. It is emitting fluorescence in different solvents including ethanol and water and sensing the $\mathrm{pH}$ within the range of $3.47-5.10$. Therefore, FCNP is convenient and general fluorescent for bioimaging applications and monitoring $\mathrm{pH}$ in living hepatoma cells (Scheme 34).

Hara et al. [47] discussed fluorinated analogues of glycosyl 1-phosphate [ $\beta$-Gal- $(1 \rightarrow 4)$ - $\alpha$-Man$[1 \rightarrow 6)-\mathrm{P}-]_{\mathrm{n}}$ which are glycosyl 1 -phosphate repeating structures found in Leishmania were synthesised using phosphoramidite method on solid-phase synthesis. It is a stepwise synthesis of glycosyl 1-phosphate has been less extensively studied than $H$-phosphonate chemistry. A compound containing five such repeating units has

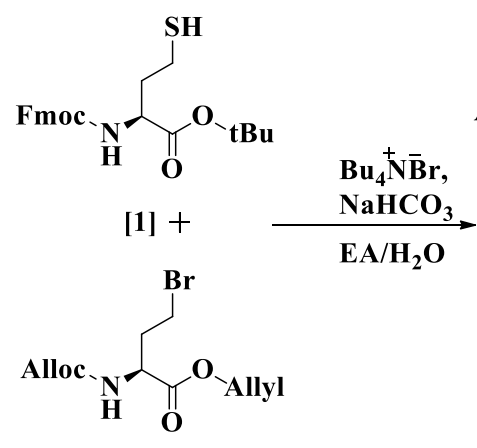

[2]

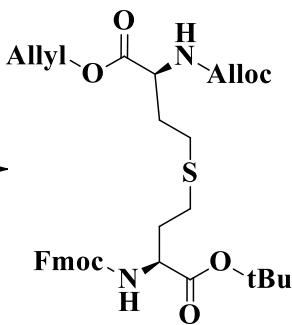

[3]

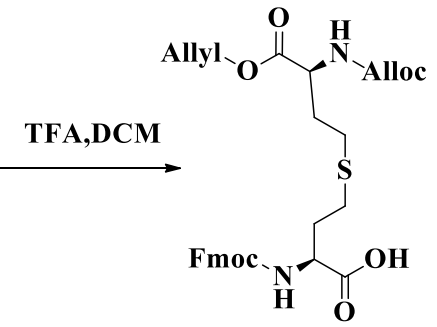

[4]

Scheme 9 The synthetic route of five-atom compound [4] 

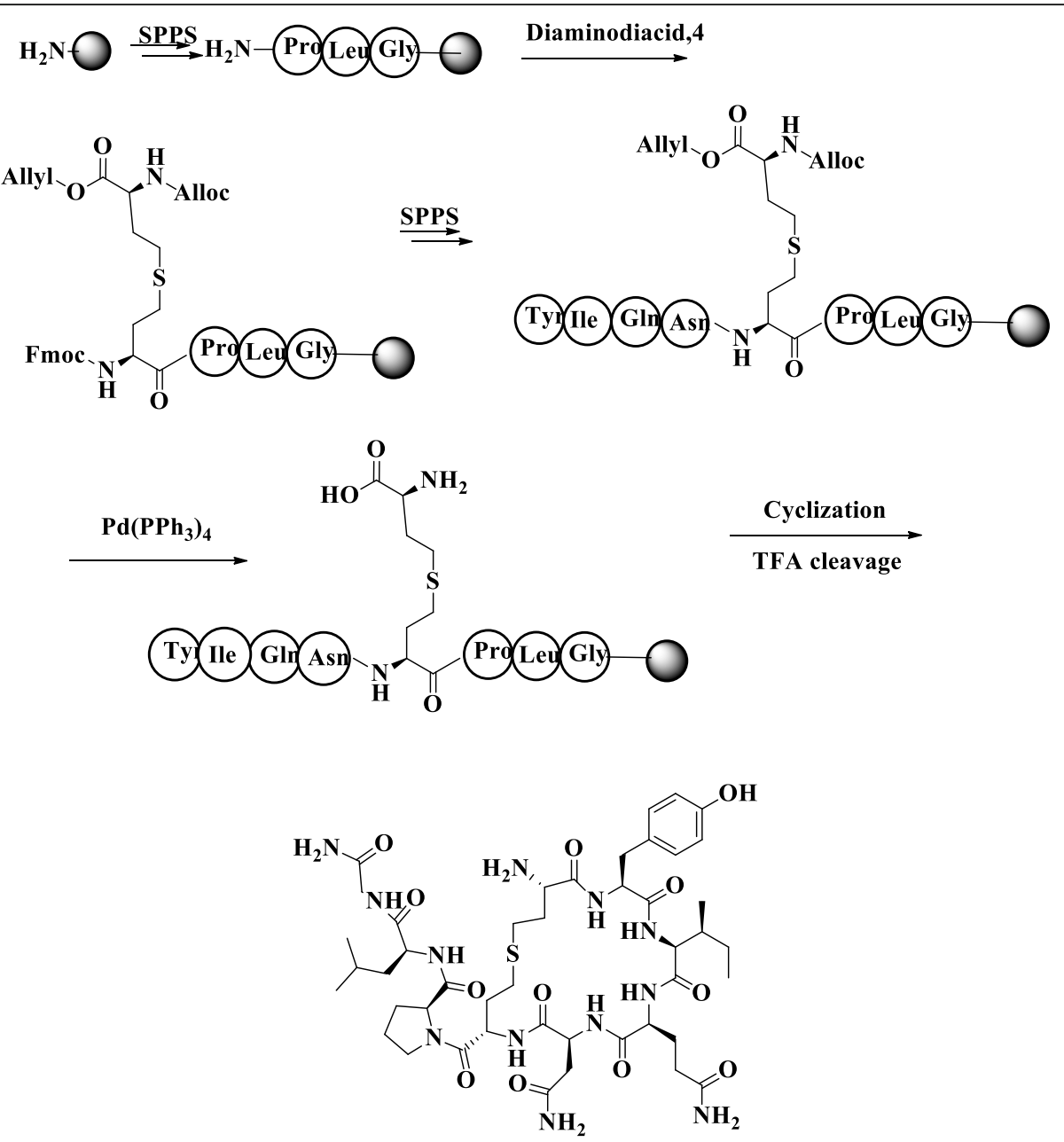

[5]

Scheme 10 Preparation of oxytocin analogue via solid-phase peptide synthesis

been constructed in a stepwise manner (Schemes $35,36,37$ and 38).

Kines and co-workers [48] synthesised a novel four series of nucleolipids with either 5methyluridine, uridine, 6-azauridine and 5fluorouridine as pyrimidine $\beta$-D-ribonucleoside using combinatorial synthesis. These synthesised compounds were characterised by ESI mass spectrometry, ${ }^{1} \mathrm{H}$-NMR, ${ }^{13} \mathrm{C}$-NMR, UV spectroscopy and elemental analysis. In addition to that, these compounds were screened for cytotoxic effect against human astrocytoma/oligodendroglioma GOS-3 and rat malignant neuroectodermal BT4Ca cell line. The result reveals that some of the<smiles>CC(C)C(=O)C1CC2(O)c3ccccc3NC2[N]1</smiles>

[1]<smiles>CC(C)NC(C[In])NC(=O)C(C)C</smiles>

[2]

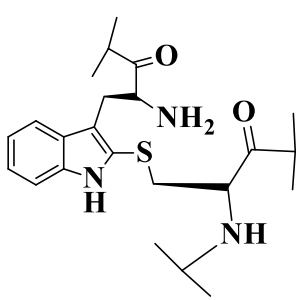

[3]

Scheme 11 General introduction of the tryptathionine crosslink [3] under acidic condition 


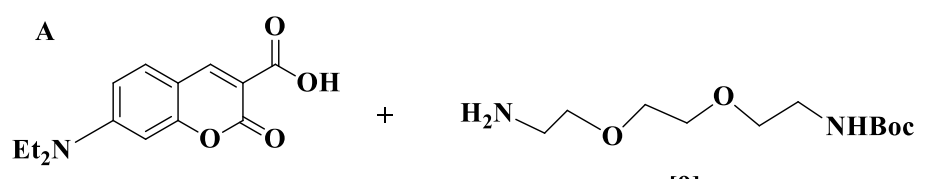

[8]

[9]

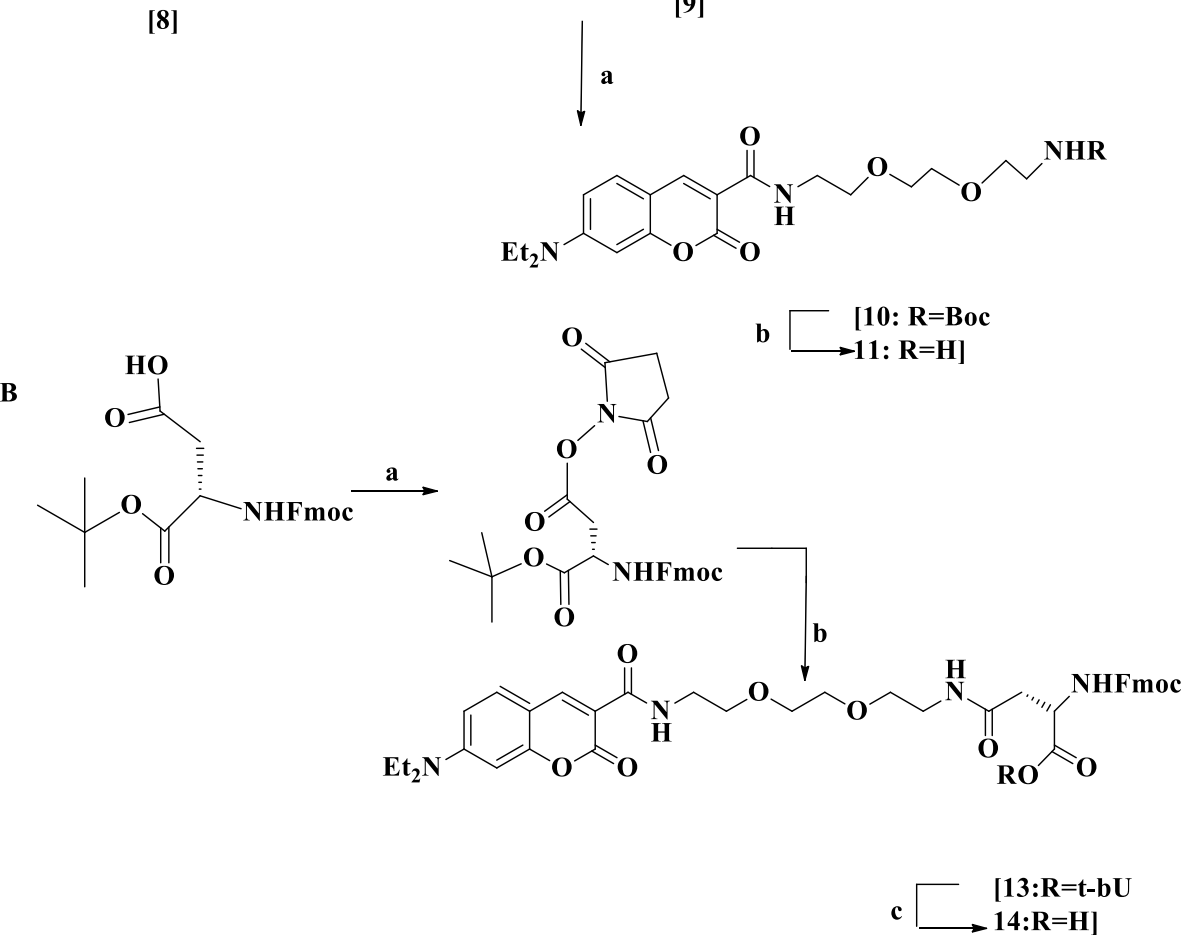

Scheme 12 Preparation of a fluorescent asparagine derivative [14]
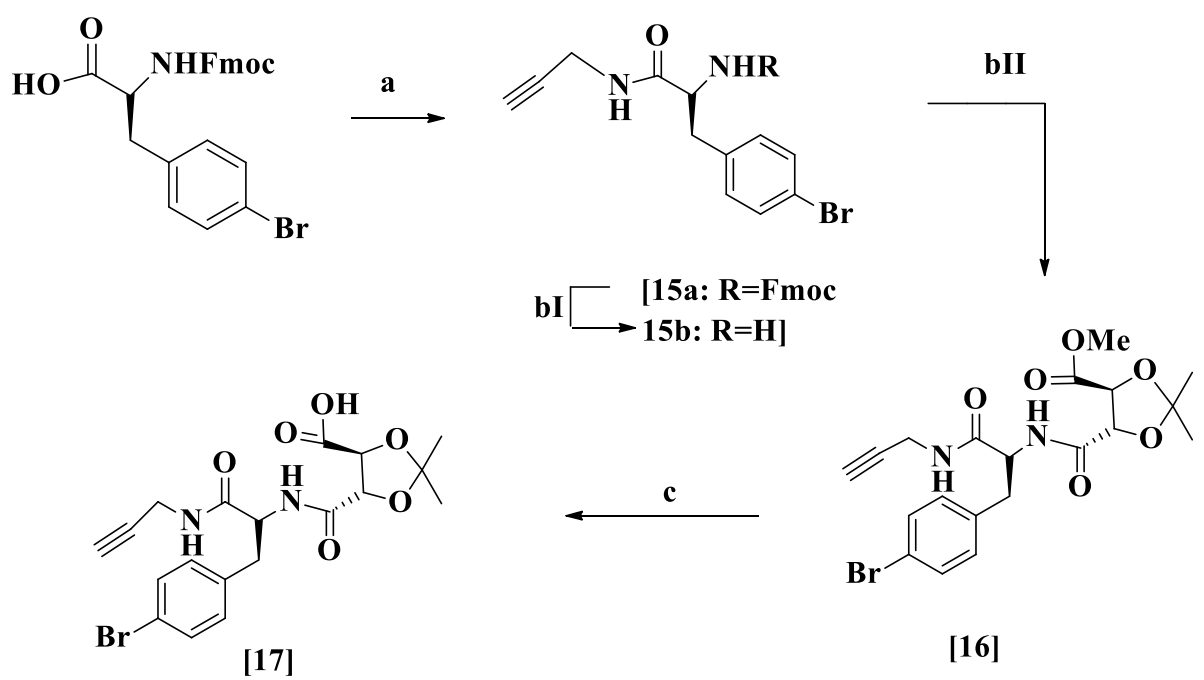

Scheme 13 Synthesis of tartrate-based linker [17] 
<smiles>CC(C)(N)COCCOCC(C)(C)COCC(C)(C)CO</smiles>

[18]

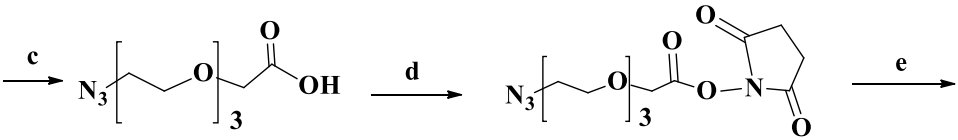

[20]

[21]

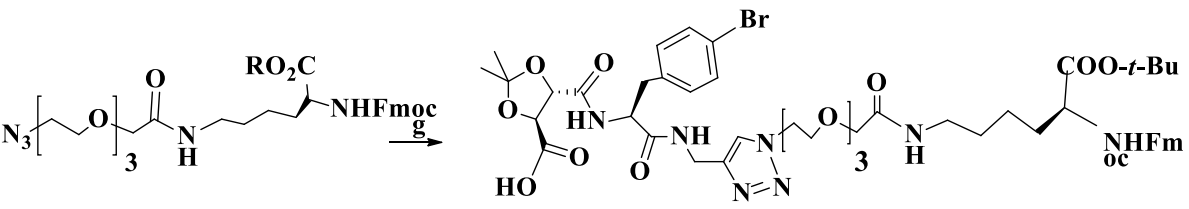

$\mathrm{f} \longrightarrow \quad \begin{aligned} & {[22: \mathrm{R}=\mathrm{H}} \\ & \longrightarrow \text { 23: } \mathrm{R}=\text { tert } \text {-Butyl] }\end{aligned}$

Scheme $\mathbf{1 4}$ Lysine condensation with the tartrate-based linker [24]

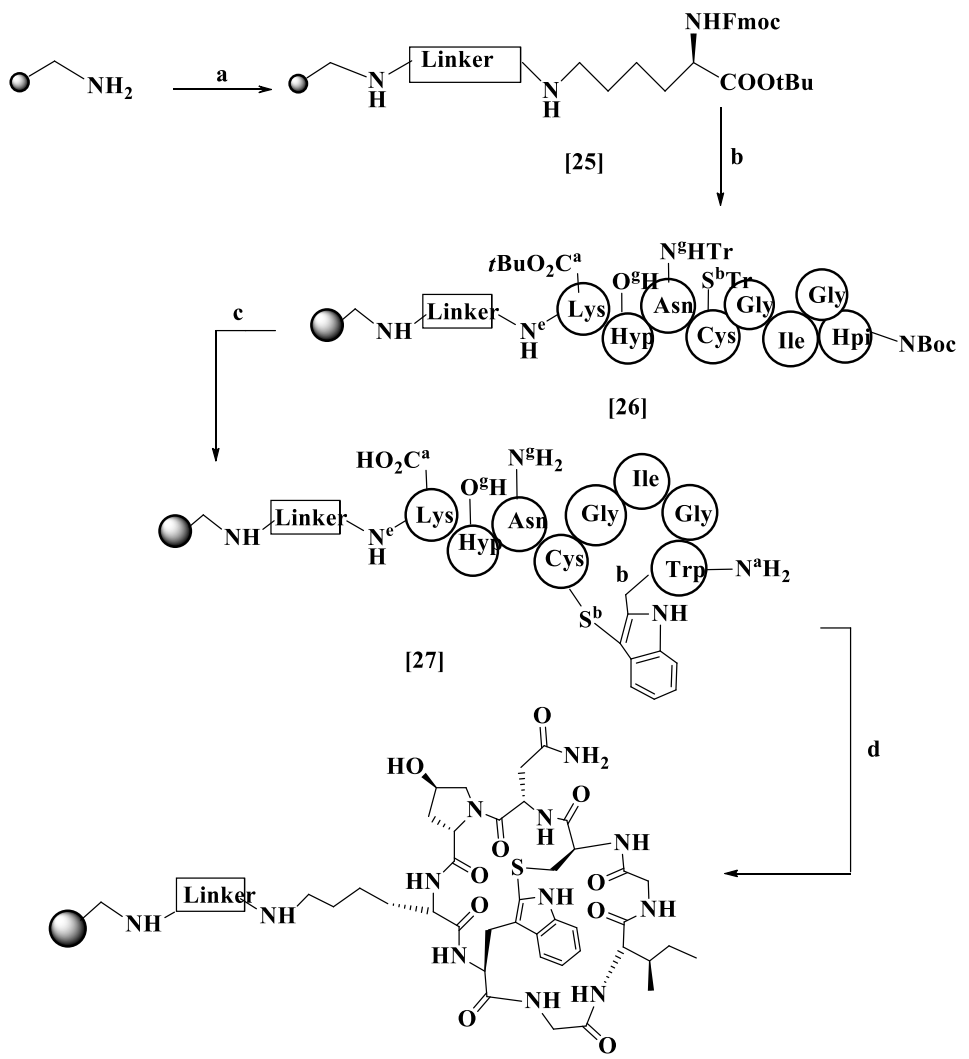

[28]

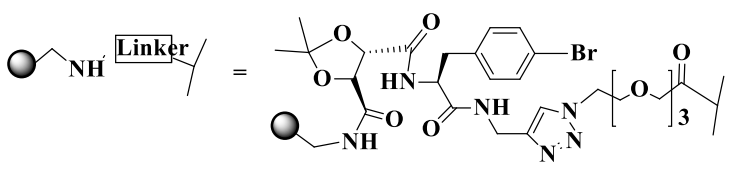

Scheme 15 Synthesis of S-deoxo-amaninamide derivative [28] 


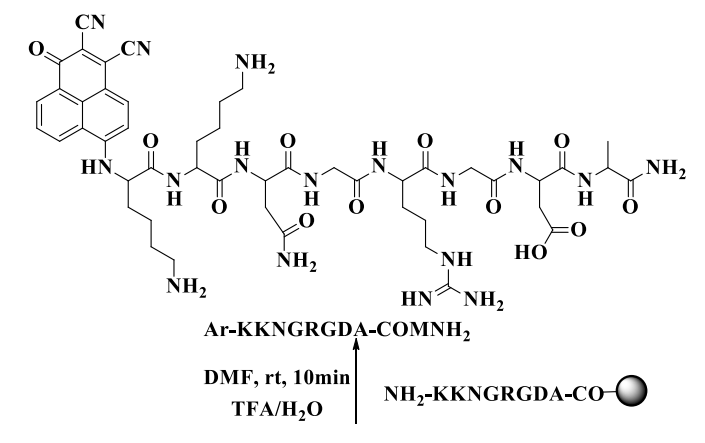

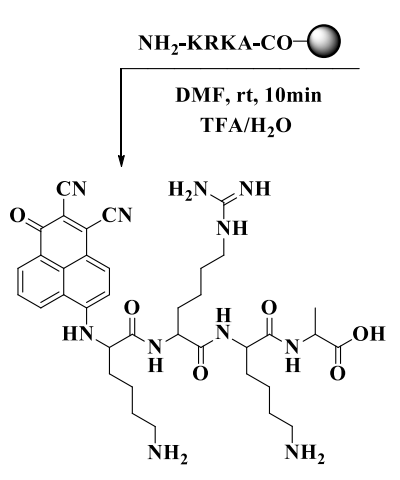

Ar-KRKA-COOH

Scheme 16 Synthesis of N-terminal modified peptides
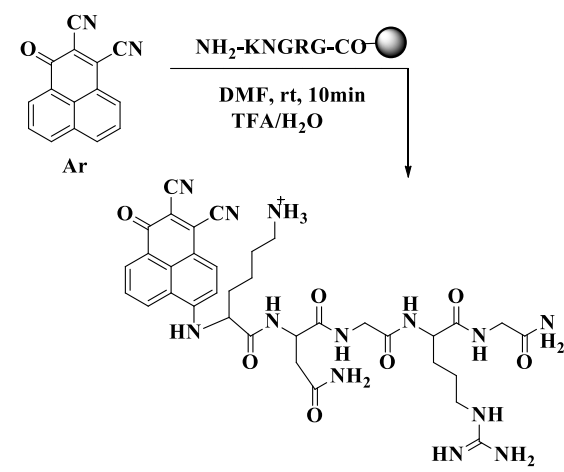

Ar-KNGRG-CONH

$$
\text { SELENON }
$$$$
\sum_{\mathrm{H}}^{\mathrm{Se}} \underbrace{\overbrace{\text { SELENOM }}}_{(49-77)} \stackrel{\mathrm{O}}{\mathrm{NR}}
$$$$
\text { 1. } 2^{\text {nd }} \text { Sec-NCL }
$$$$
\text { 2. Deselenization }
$$$$
\text { 3. Deprotection }
$$

HSe

$\checkmark$
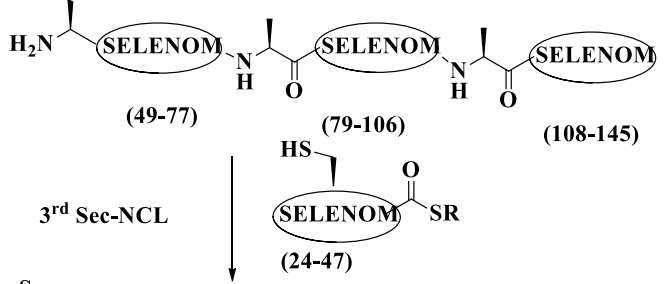

S-Se

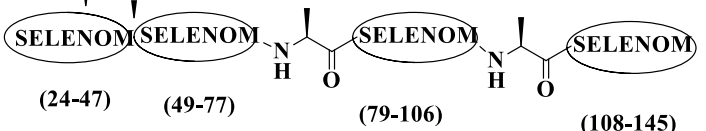

Scheme 17 Three-step synthesis of selenocysteine exemplifies the use of the Sez protecting group for Sec-mediated NCL under reducing conditions 

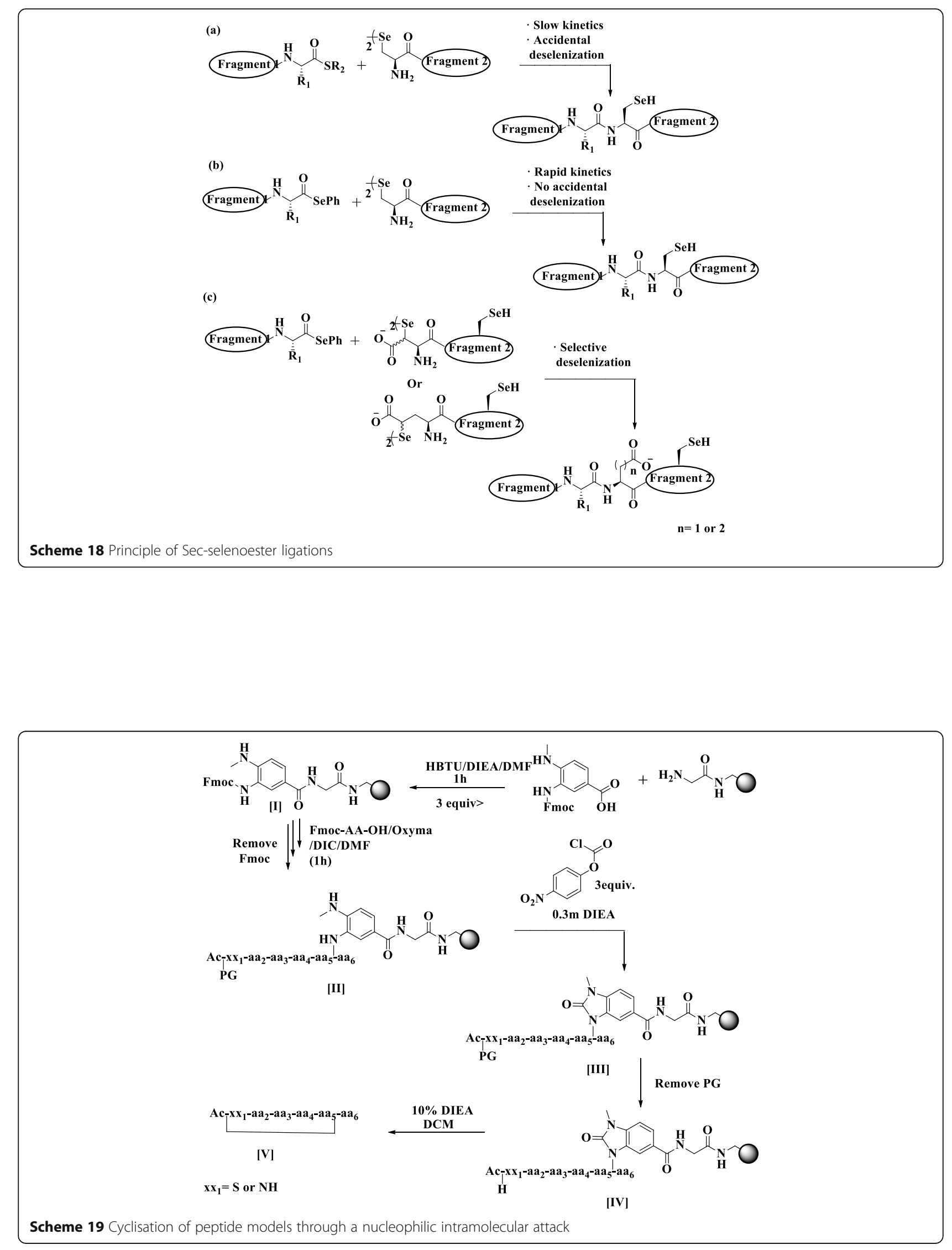


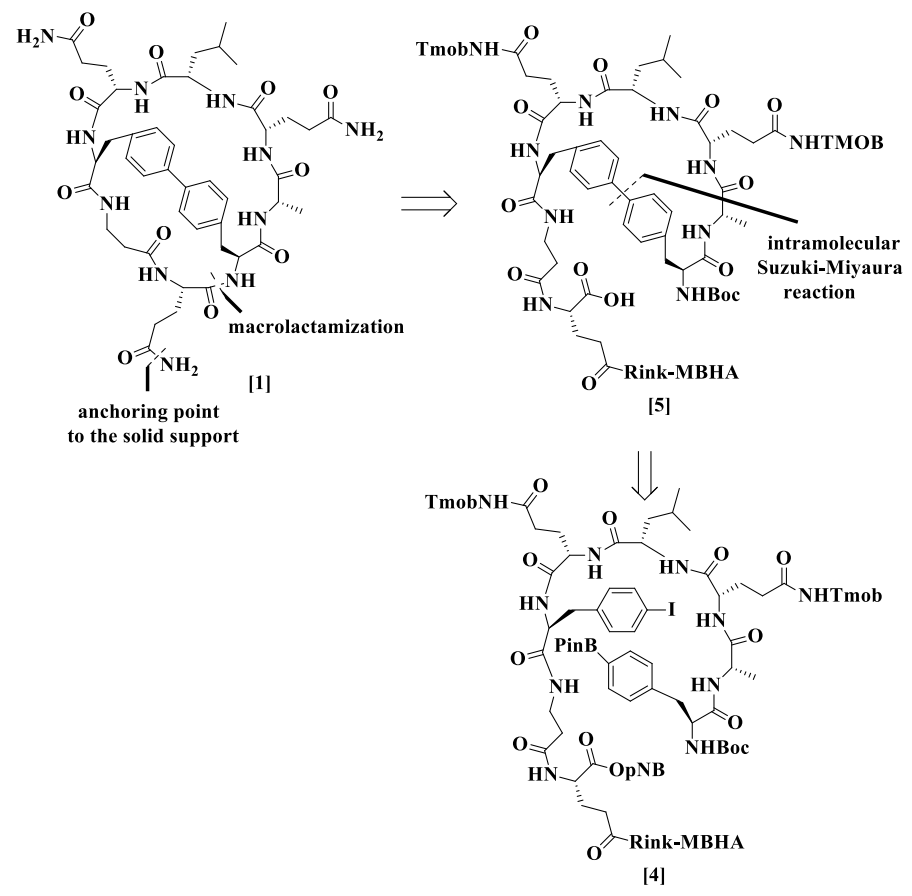

Scheme 20 Retrosynthetic analysis for the biaryl bicyclic peptide [1]

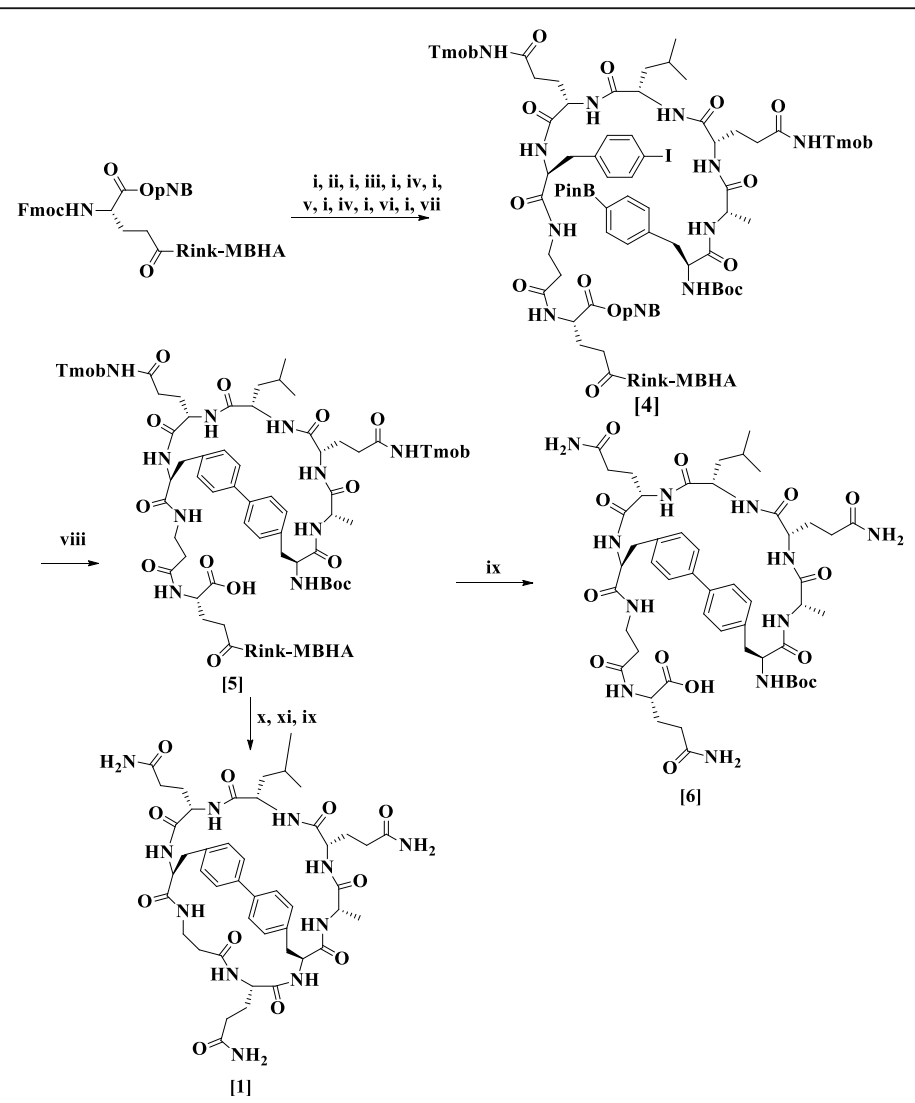

Scheme 21 Synthesis of the biaryl bicyclic peptide 1 incorporating a Phe-Phe linkage 


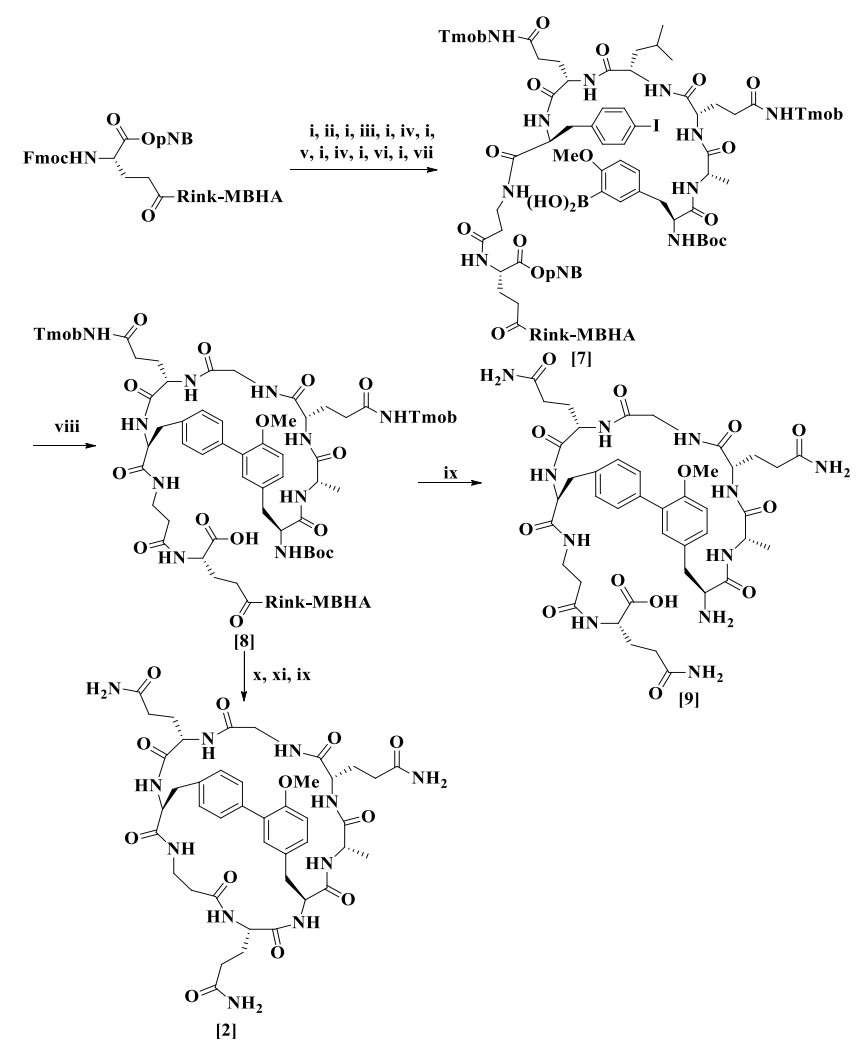

Scheme 22 Synthesis of the biaryl bicyclic peptide 2 incorporating a Phe-Tyr linkage

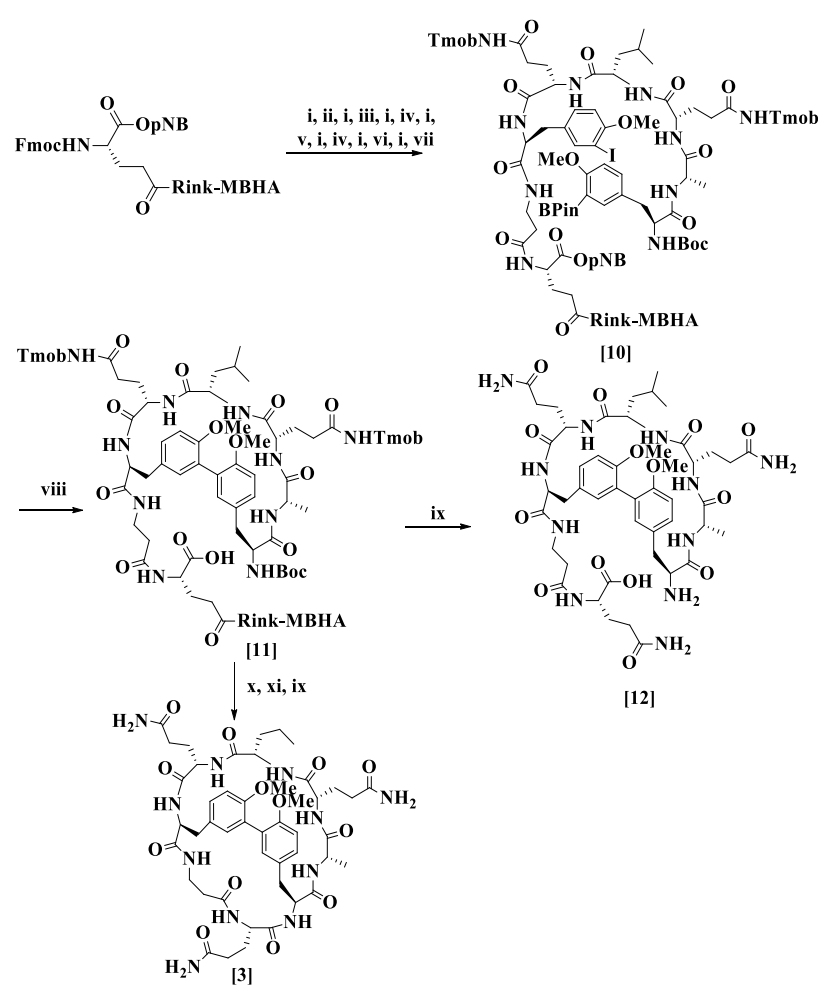

Scheme 23 Synthesis of the biaryl bicyclic peptide 3 incorporating a Tyr-Tyr linkage 

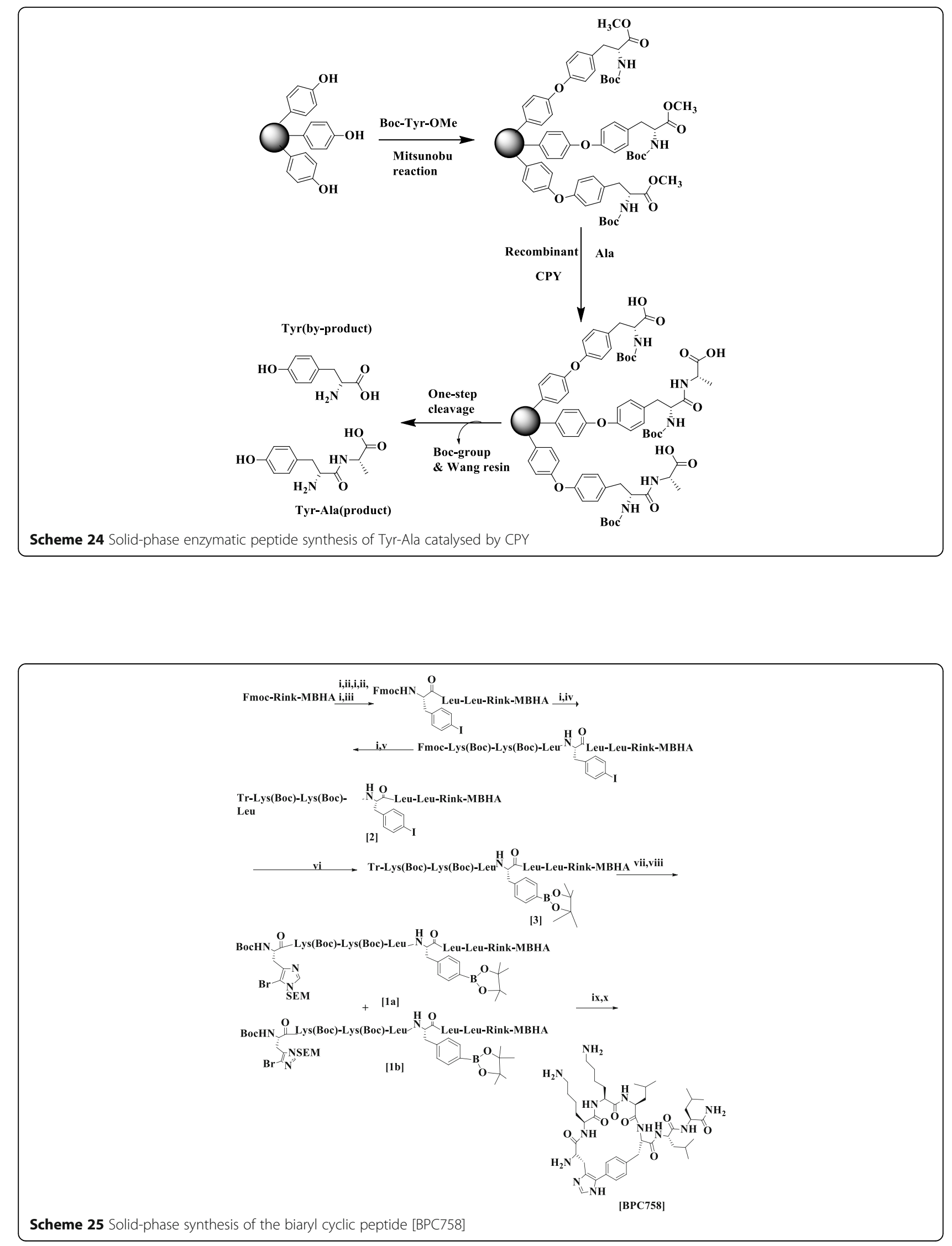


\title{
Tr-Lys(Boc)-Lys(Boc)-Leu-Phe(4-I)-Rink-MBHA
}

\author{
i,ii,iii \\ Boc-His(5-Br,1-SEM)-Lys(Boc)-Lys(Boc)-Leu-Phe(4-BPin)-Rink-MBHA \\ $+$ \\ Boc-His(5-Br,3-SEM)-Lys(Boc)-Lys(Boc)-Leu-Phe(4-BPin)-Rink-MBHA
}

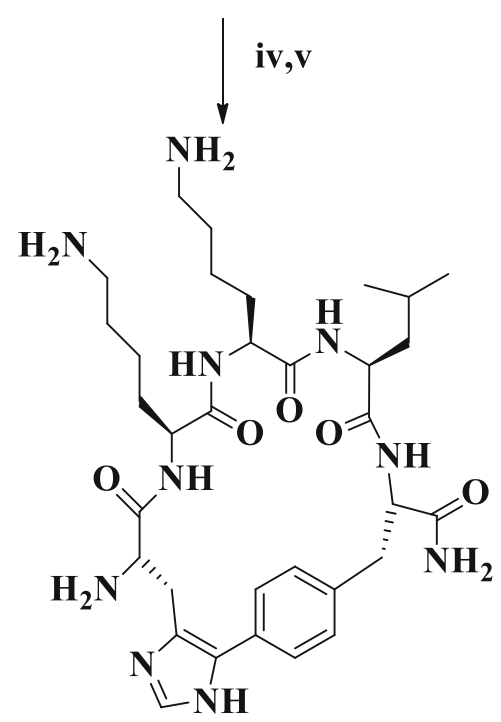

[BPC750]

Scheme $\mathbf{2 6}$ Synthesis of biaryl cyclic peptides [BPC750]

compounds with $\mathrm{N}(3)$ of the pyrimidine has shown the highest probability of killing cancer cells compared with other molecules (Schemes 39 and 40).

Murray et al. [49] identified an easy access to a range of functionalised long-chain alkanethiol oligoethyleneglycols on gold by using solid-phase synthesis. The versatility of synthetic procedure was demonstrated by synthesising LCAT-OEGs with the range of a functional group of the peptide, electroactive redox group for post-assembly conjugation. Finally, the synthesised compound was characterised by XPS, EIS, APM, contact angle measurements and colorimetric method etc. (Schemes 41 and 42).

\subsubsection{Synthesis of inorganic compounds}

Kerbel et al. [50] prepared cathode material-based lithium iron phosphate powders $\left(\mathrm{LiFePO}_{4}\right)$ in the air without the help of inert or reducing medium through continuous solid-phase synthesis. The nanostructured crystal composites of lithium iron phosphate powders are formed by bottom-up selfassembly, resulting in dispersive, crystalline globular solid and has been used to identify the discharge capacity of synthetic powder. The high concentration of these composites of lithium iron phosphate powders prevented degradation and enhances their absolute values while cycling (Scheme 43).

Li et al. [51] found a simple and convenient way for the synthesis of $\mathrm{CU}_{2} \mathrm{MOS}_{4}$ nanoparticles by using the solid-phase method. It is a novel technique introduced for the first time in the synthesis of $\mathrm{CU}_{2} \mathrm{MOS}_{4}$ nanoparticles and the $\mathrm{CU}_{2} \mathrm{MOS}_{4}$ nanoparticles were evaluated by using $\mathrm{X}$-ray photoelectron spectroscopy, field emission scanning electron microscopy, X-ray diffraction and UV-visible spectrophotometry. It is the best method for a produced photocatalytic agent when compared with other existing methods (Scheme 44).

Kalinkin et al. [52] synthesised a nanocrystalline lanthanum zirconate $\left(\mathrm{LaZr}_{2} \mathrm{O}_{7}\right)$ by a solid-phase technique using mechanical activation of a $\mathrm{La}_{2} \mathrm{O}_{3}$ and $\mathrm{ZrO}_{2}$. Hence, the reaction took place between them with the aid of heat and was evaluated by X-ray phase analysis and transmission electron microscopy techniques (Scheme 45). 
Tr-Leu-Phe(4-1)-Leu-Leu-Rink-MBHA<smiles>C1=C[Al][Al]1</smiles>

Boc-His(5-Br,1-SEM)-Leu-Phe(4-BPin)-Leu-Leu-Rink-MBHA (8a)

$+$

Boc-His(5-Br,3-SEM)-Leu-Phe(4-BPin)-Leu-Leu-Rink-MBHA (8b)

iv, $\mathbf{v}$

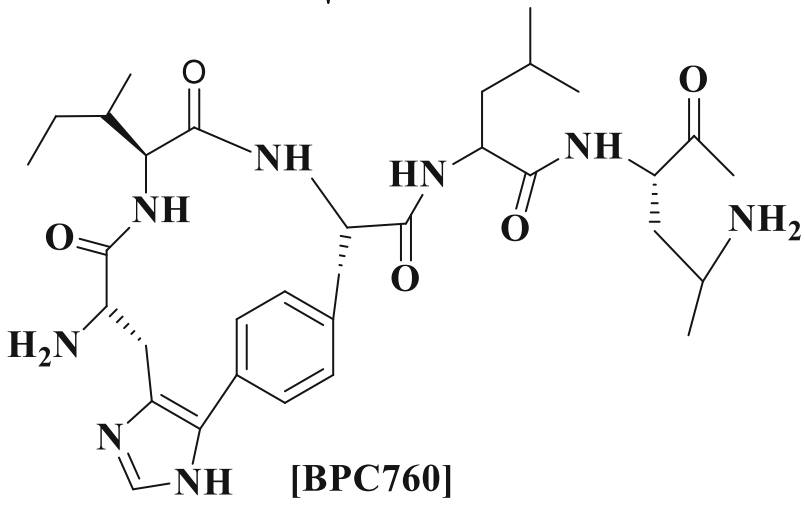

Tr-Leu-Phe(4-1)-Rink-MBHA

i,ii,iii

Boc-His(5-Br,1-SEM)-Leu-Phe(4-BPin)-Leu-Leu-Rink-MBHA (8a)

$+$

Boc-His(5-Br,3-SEM)-Leu-Phe(4-BPin)-Leu-Leu-Rink-MBHA (8b)<smiles>CCC(C)C1NC(=O)[C@H](N)Cc2nc[nH]c2-c2ccc(cc2)[C@H](N)C(=O)NC1C(N)=O</smiles>

[BPC752]

Scheme 27 Synthesis of biaryl cyclic peptides [BPC760 and BPC752]

\subsection{Solution-phase synthesis}

Despite the solid-phase technique, some of the combinatorial libraries were synthesised and screened for their biological activities by solution-phase synthesis using parallel or split and mix procedure [53-55]. This process is inappropriate for the multistep synthesis because it required tedious purification in each step as compared with solid-phase synthesis 


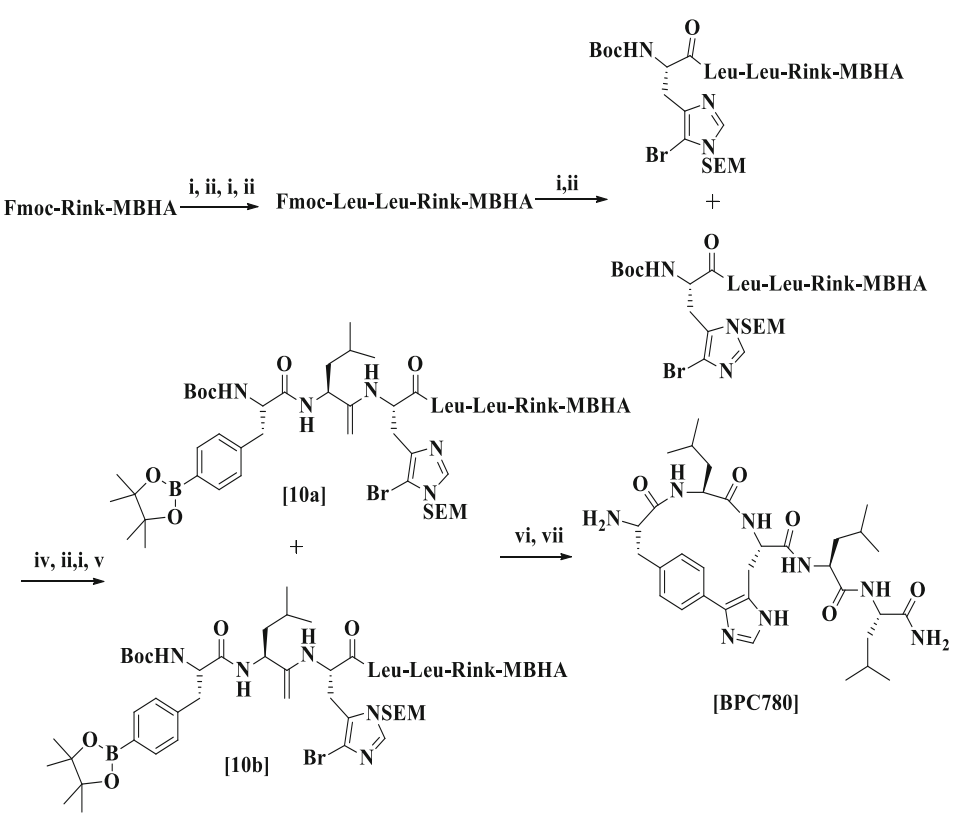

Scheme $\mathbf{2 8}$ Synthesis of biaryl cyclic peptide [BPC780]

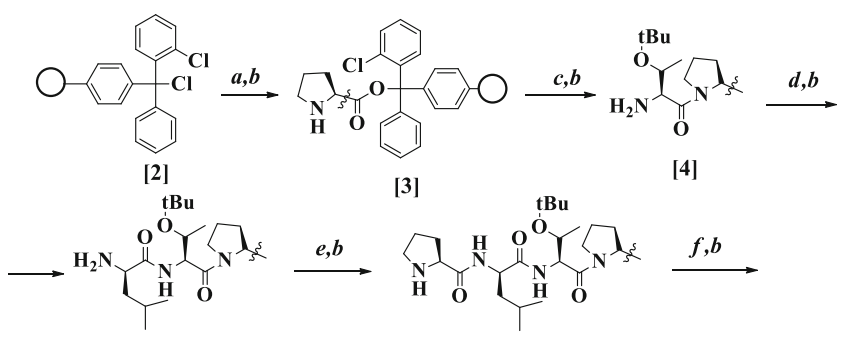

[5]

[6]
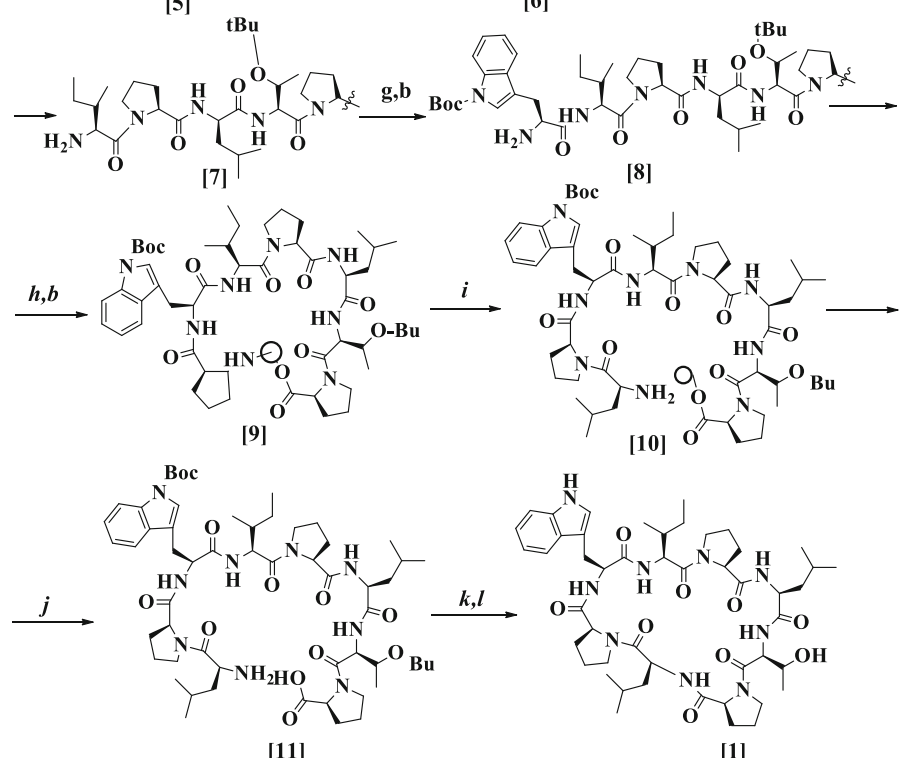

Scheme 29 Solid-phase synthesis of cyclic octapeptide phakellistatin [15] 


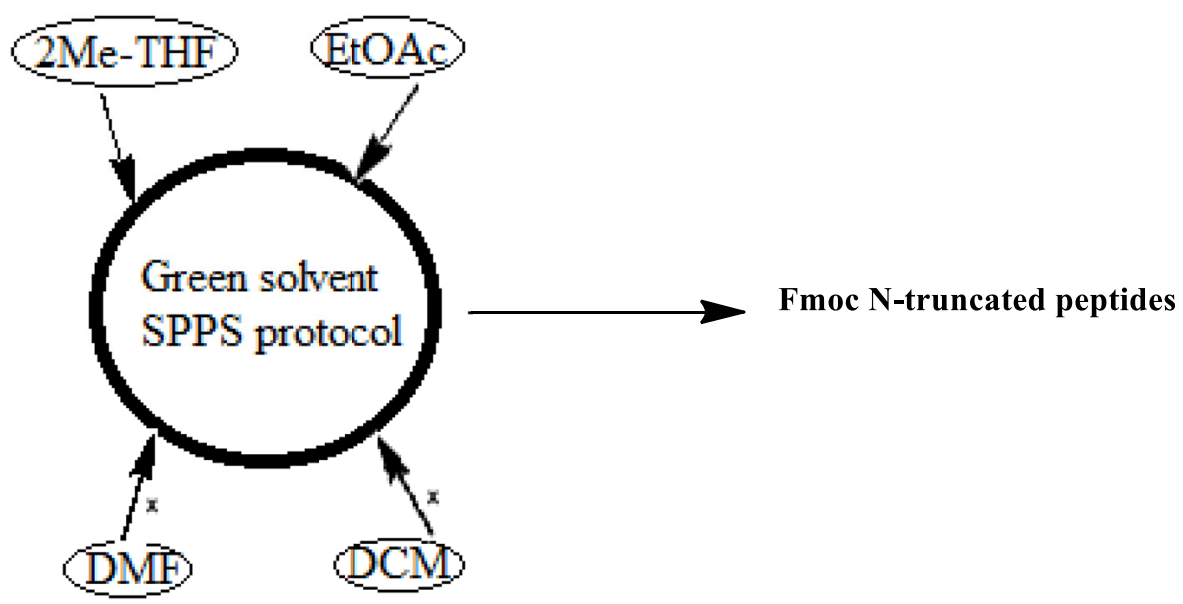

Scheme $\mathbf{3 0}$ Green solid-phase peptide synthesis

[56]. So that majority of the compounds were synthesised by using solid-phase synthesis (Fig. 4).

\subsubsection{Synthesis of organic and peptide compounds}

A group of researchers led by Khan et al. [57] have developed the microwave-assisted synthesis of thirtyeight $N$-aroyl- $N$-aryl thiourea libraries using solution-phase synthesis. In silico docking studies of title compounds were carried out against urease enzyme that acts as a target for lung carcinoma. The studies showed detailed information about the binding mode of title molecules with the targeted site and found an excellent score from compound 17. Later, these analogues were prepared from the raw materials using a similar set of conditions. The authors of the manuscript would like to test the potency of compound 17 with different types of cell lines (Scheme 46).

Kohout et al. [58] prepared a complex sugar molecule using a single coupling protocol or set of reagents. He used a well-known reaction of benchchemistry to achieve the goal of synthesis of a broad range of glycans from sugar fragments. Here, di and trisaccharides of $1 \rightarrow 2$ rhamnan fragments were prepared using a $N$-thioglycoside donor through the solution-phase synthesis in the presence of $N$-iodosuccinamide and trimethylsilyl triflate. Byproducts are compatible with hydrazine-based deprotection conditions, lending broader functionality to this method (Scheme 47, 48 and 49).

Skoblov et al. [59] synthesised a novel N-TFAprotected carboxyrhodamine 6G (R6G) phosphoramidite

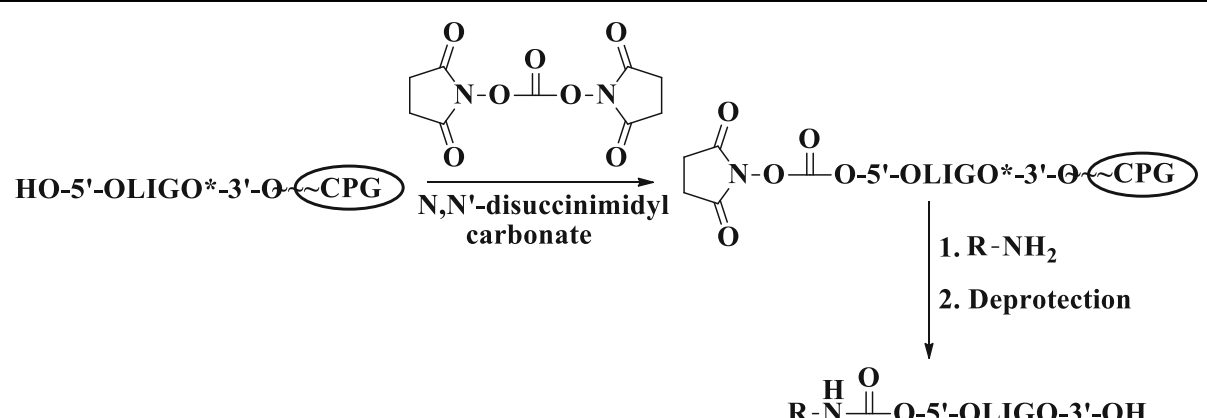

OLIGO*: protected oligonucleotide (ribo-, deoxy-, 2'-O-methylribo-types) with free 5'-hydroxyl group

OLIGO: unprotected oligonucleotide

CPG : controlled pore glass

$\mathrm{R}-\mathrm{NH}_{2}$ : amino ligands

Scheme 31 Synthesis of 5'-functionalisation of oligonucleotides (ribo-, deoxyribo-, 2'-O-methylribo-) 

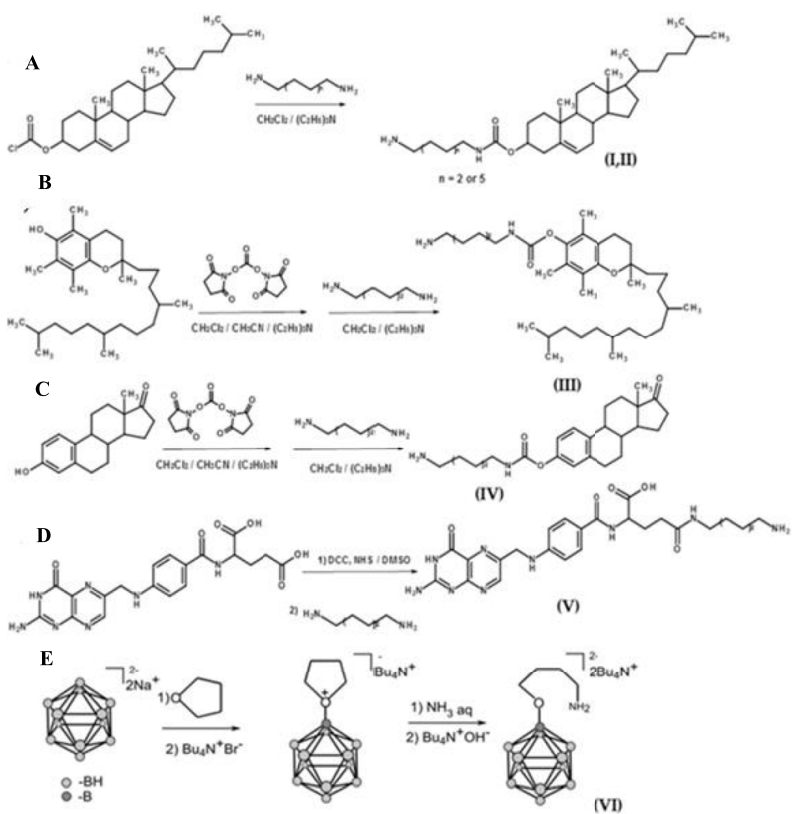

Reagents and conditions: (a) cholesterols (I,II), (b) alpha-tocopherol (III), (c) estrone (IV), (d) gama-amino-modified

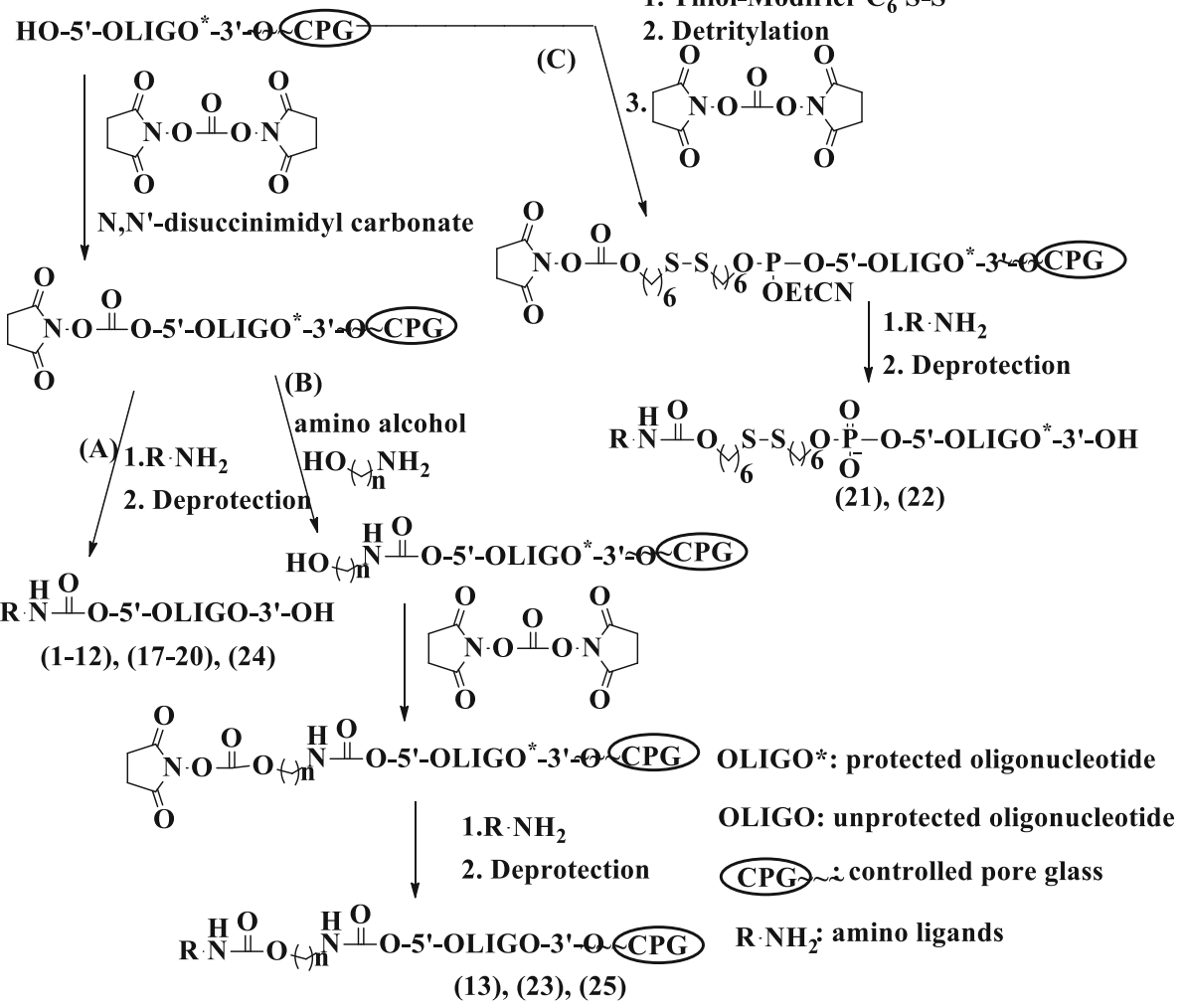

Scheme $\mathbf{3 3}$ Synthesis of $5^{\prime}$-conjugates of oligonucleotides based on DSC activation 


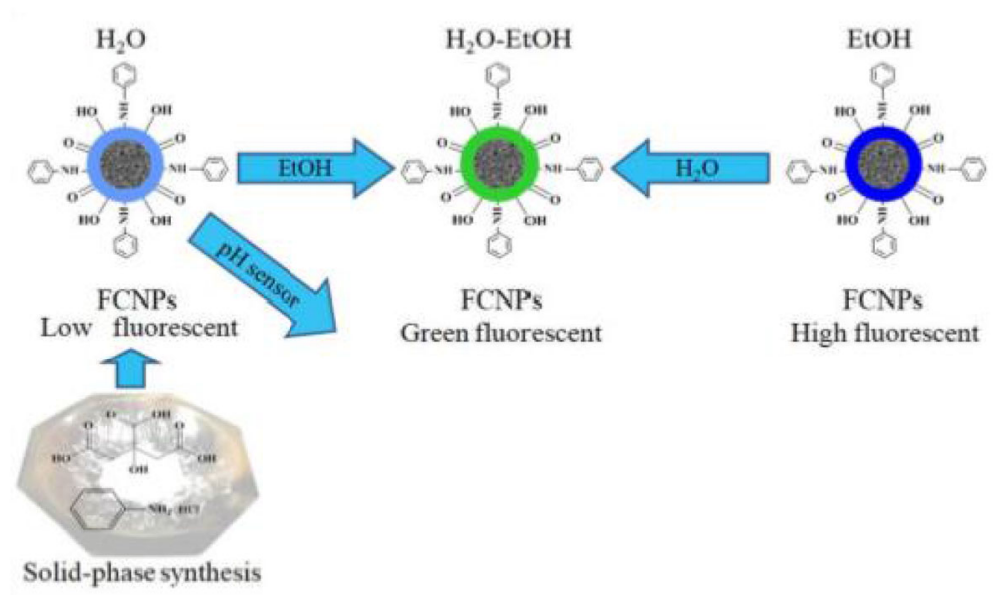

Scheme 34 Synthesis of highly fluorescent carbon nanoparticles

compound through solid and solution phases. An automated DNA method had been used to synthesis the mentioned compound and deprotection \& purification condition were optimised 5 -labelled and dual-labelled oligonucleotide probes. The authors also prepared an azide derivative of R6G for CuAAC post-synthetic oligonucleotide labelling as an alternative compound. Both the method has shown the same efficacy in a quantitative PCR assay (Scheme 50, 51, 52 and 53).
Tang et al. [60] discussed the novel method of synthesis of $\beta-1,2-, 1,3-, 1,6$-mannan oligomers by applying the $\beta$-directing $C-5$ carboxylate technique using automated solution-phase synthesis. Each synthetic step cycle allowed short $\beta$-mannan oligomers with a limited amount of glycosyl donor to purify the product by the fluorous-tag-assisted method. The study encourages the preparation of different challenging glycosides using automated solutionphase synthesis (Schemes 54, 55, 56 and 57).
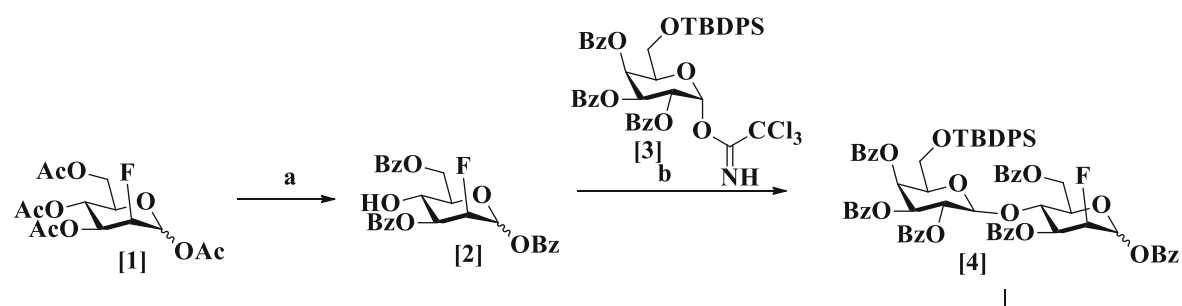

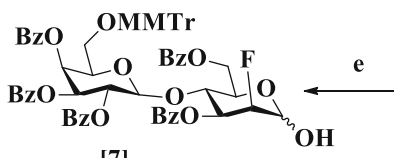

[7]<smiles>[3H]</smiles>

BzO OMMTr

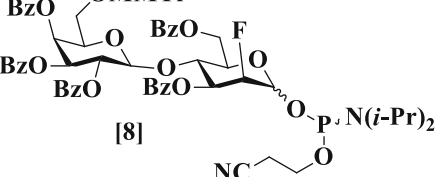

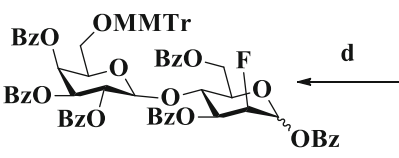

[6]

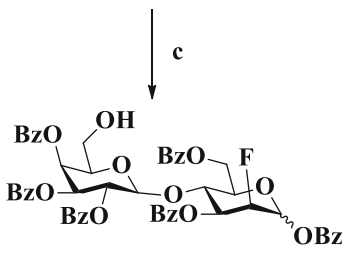

[5] 


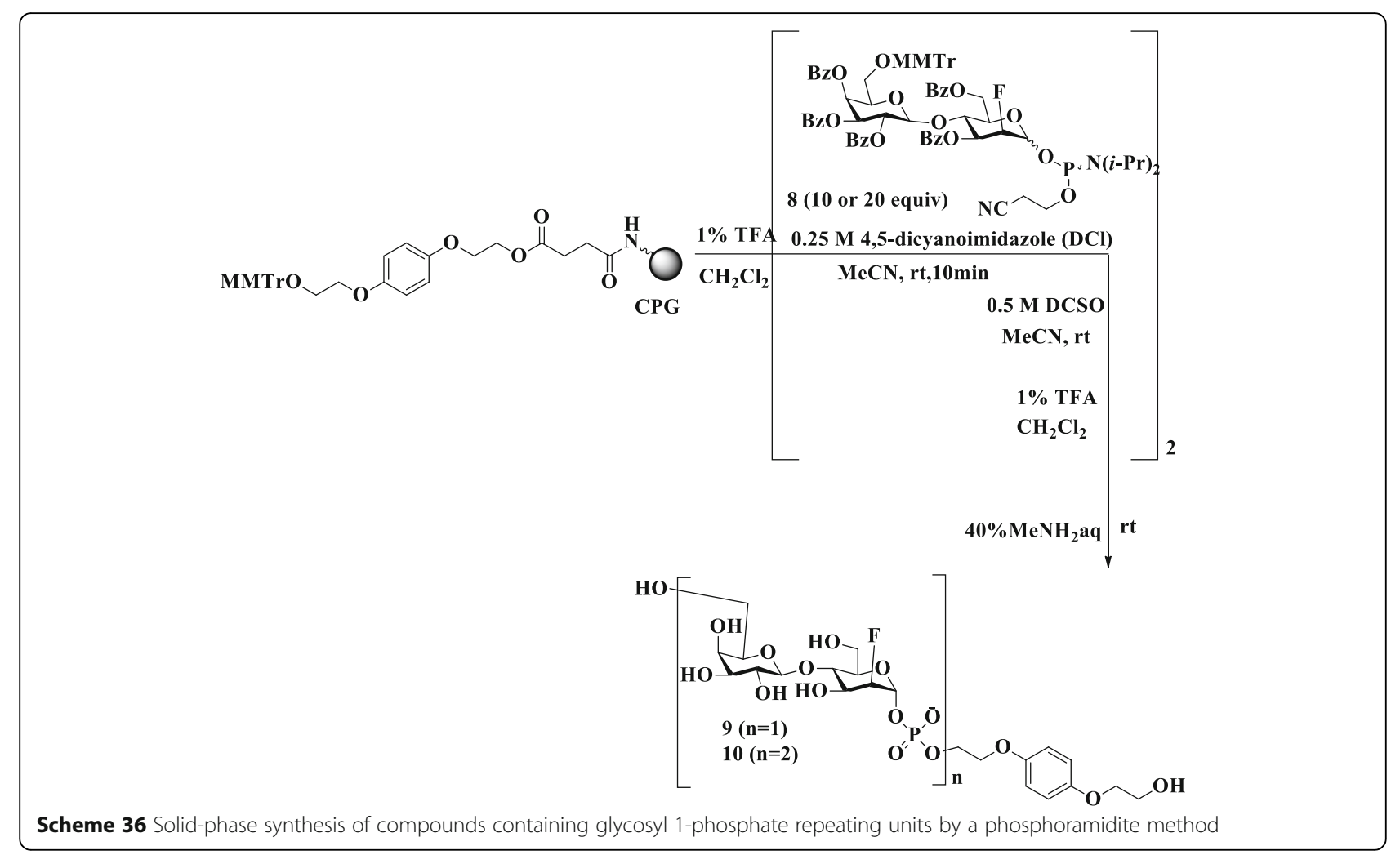

Ryakhovsky et al. [61] synthesised Melanotan II by solution-phase synthesis using hexapeptide sequence assembled $[(2+2)+1+1]$ scheme. The titled compound was prepared by the interaction of cyclic intermediate and $\mathrm{N}$-acetylnorleucine. Initially, the $\varepsilon$ - amino acid group, including a $\gamma$-carboxy group of aspartic acid, lysine, was involved in the formation of a cyclic intermediate. Later, $\mathrm{N}$-acetylnorleucine converted the intermediate into a Melanotan II molecule. The mentioned method offered a greater

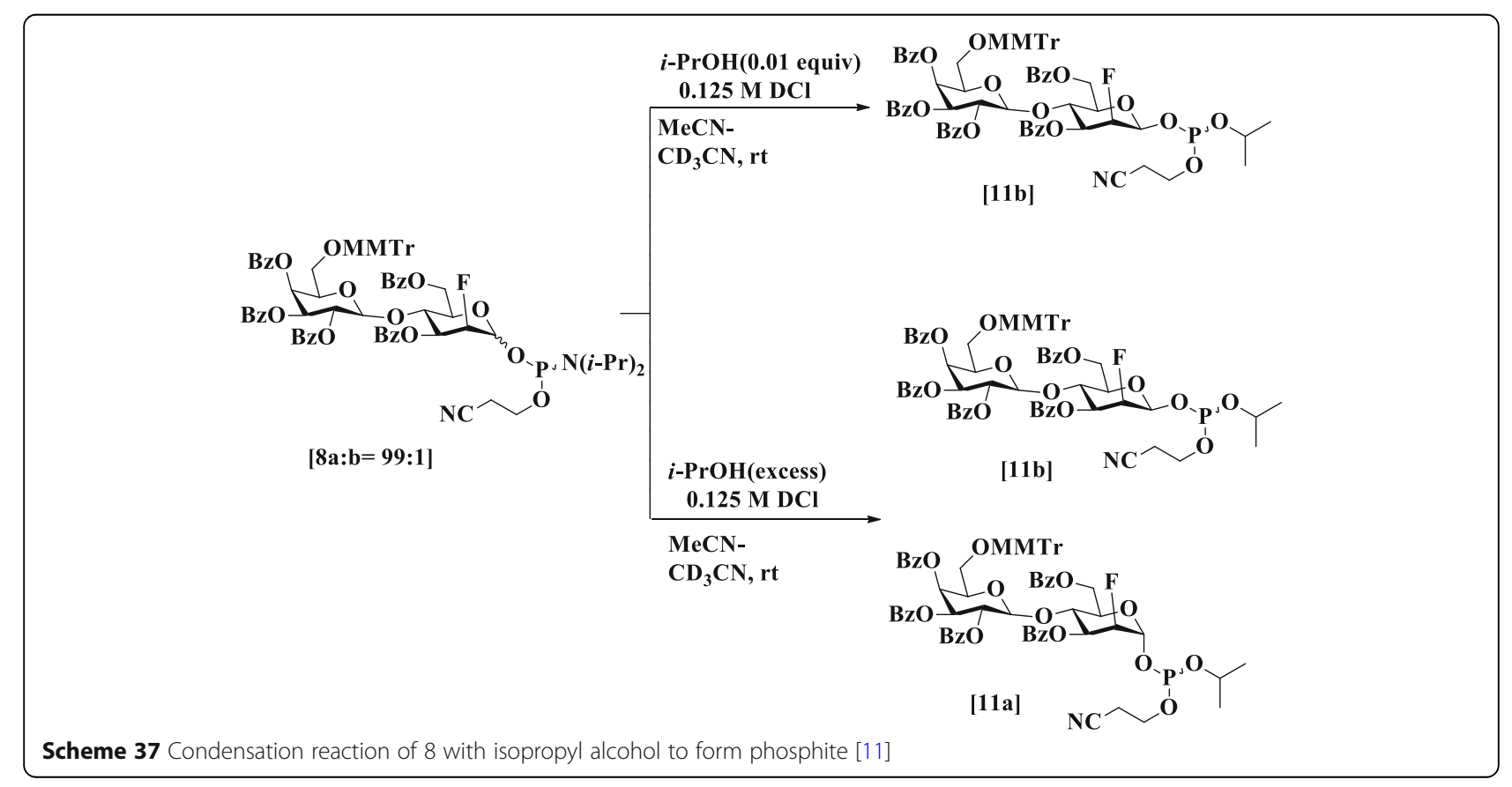




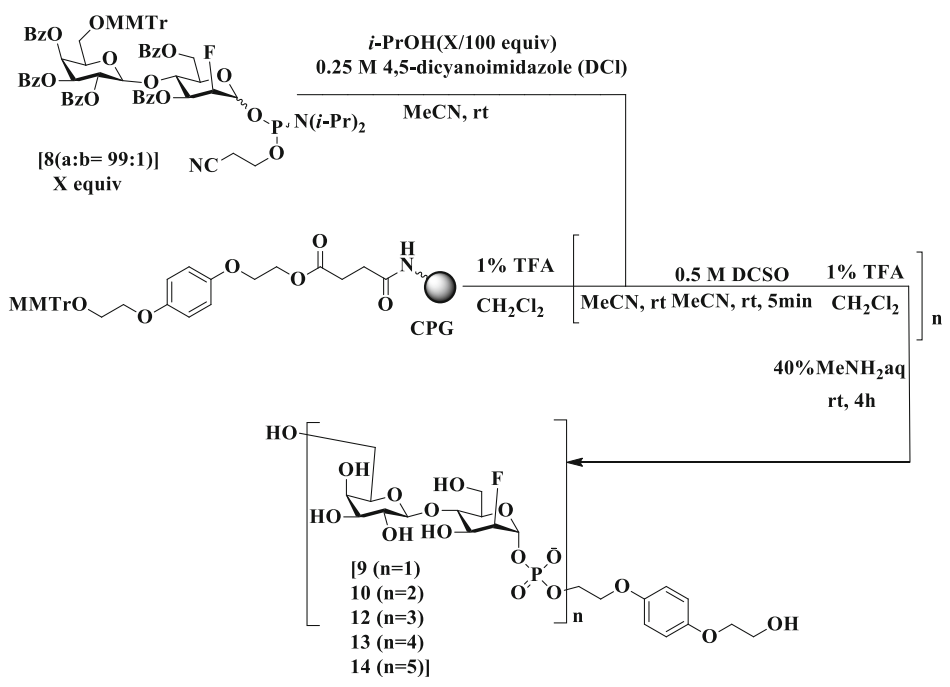

Scheme 38 Modified solid-phase synthesis containing a pre-activation step for phosphoramidite [8]

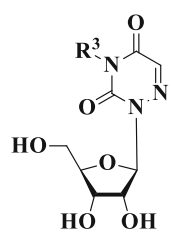

[1]

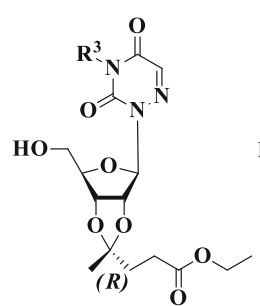

[2]

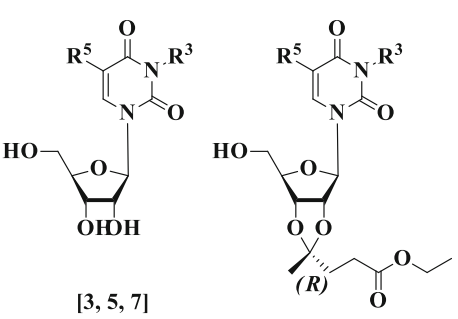

$[4,6,8]$

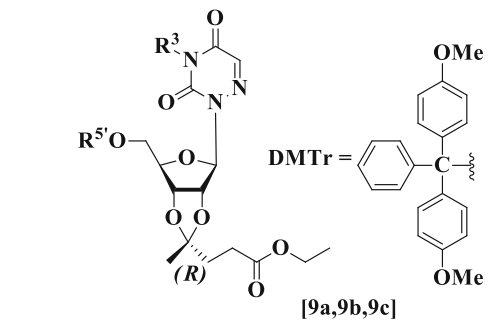

\begin{tabular}{l|ll} 
& $\mathbf{R}^{3}$ & $\mathbf{R}^{5^{\prime}}$ \\
\hline $9 \mathrm{a}$ & $\mathrm{H}$ & $(\mathbf{P r})_{2} \mathrm{CHCO}$ \\
$9 \mathrm{~b}$ & $\mathrm{H}$ & DMtr \\
$9 \mathrm{c}$ & $(\mathbf{P r})_{2} \mathrm{CHCO}$ & DMtr
\end{tabular}

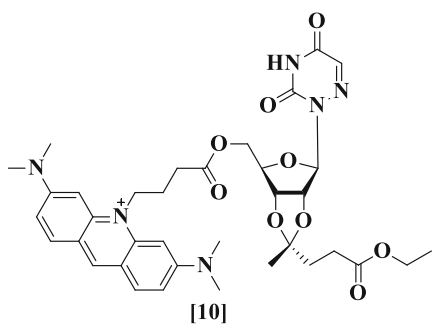

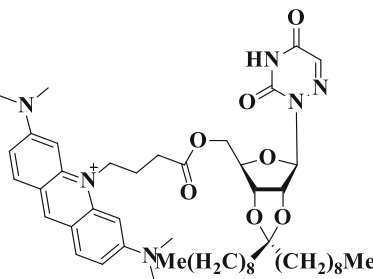

[11]
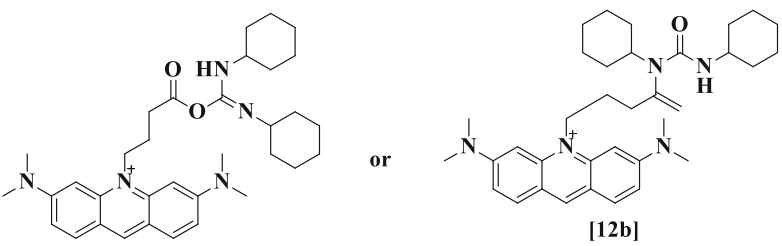

[12a]

Scheme 39 Synthesis of novel nucleolipides of pyrimidine $\beta$-D-ribonucleosides [1-12]. 


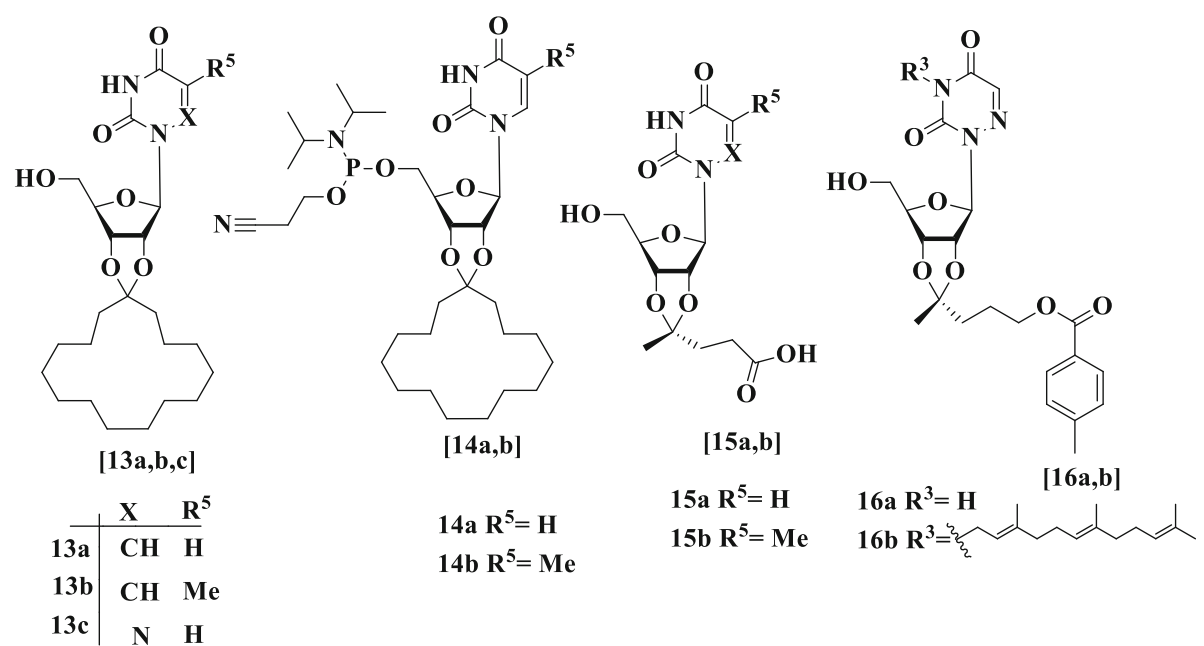

Scheme $\mathbf{4 0}$ Synthesis of novel nucleolipides of pyrimidine $\beta$-D-ribonucleosides [13-16]

percentage yield of product and obtained purity nearly > 90\% (Scheme 58).

\subsubsection{Synthesis of inorganic compounds}

Fenton et al. [62] reported metal tellurides are vital materials used for different applications such as photovoltaic, catalytic and thermoelectric purposes. Hence, he came up with a novel method of synthesising the nanoscale transition metal tellurides by the interaction of pre-formed colloidal metal nanoparticle and bis(trimethylsilyl)telluride using solution-phase synthesis. Nanoparticle Pd, Ni and Pt were used to synthesise corresponding transition metal tellurides.
The formation of metal telluride has been controlled by the reactivity of tellurium reagents (Scheme 59).

Kambe et al. [63] synthesised a superatom $\mathrm{Al}_{13}{ }^{-}$ using a dendrimer template by solution-phase synthesis. It is a well-known superatom developed as clusters with tunable properties and have been identified through mass spectrometry, X-ray photoelectron spectroscopy and scanning transmission of electron microscopy. Later, the superatomic stability of $\mathrm{Al}_{13}{ }^{-}$is demonstrated by evaluating its tendency towards oxidation. Solution phase synthesis contributed a vital role in cluster science by making different superatoms (Scheme 60).

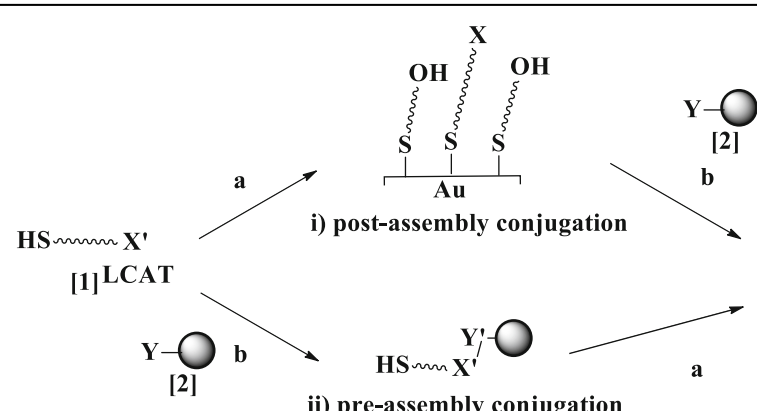

ii) pre-assembly conjugation

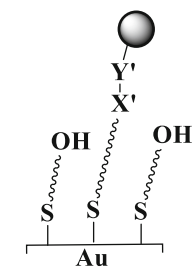

[3] functionalised SAM

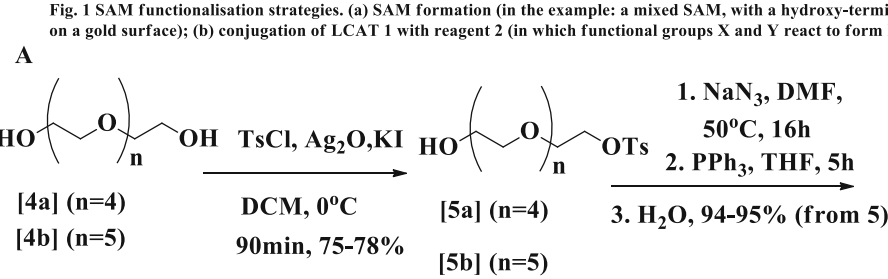

$\mathrm{NaN}_{3}, \mathrm{DMF}$,

$50^{\circ} \mathrm{C}, 16 \mathrm{~h}$

[4a] $(n=4)$

90min, $75-78 \%$

$[5 b](n=5)$ 
B<smiles>NCCOCCO</smiles><smiles>CC(O)(O)COCCNC(=O)C=S</smiles>

[11a] (n=1),74\% (from 8)

$\mathrm{O}_{[8]}^{-\mathrm{Cl}}$

DCM, 16h

2. MeOH, DIPEA

DCM, 2'2 min

$[11 b](n=1), 62 \%$ (from 8$)$

\section{$\uparrow$}

65\% TFA IN DCM

TES, 3'2 min
$\mathrm{HS}_{4} \underset{10}{\mathrm{O}} \underset{\mathrm{H}}{\mathrm{N}} \sim(\mathrm{O})_{5} \mathrm{~N}_{3}$

$13,35 \%$ (from 8 )

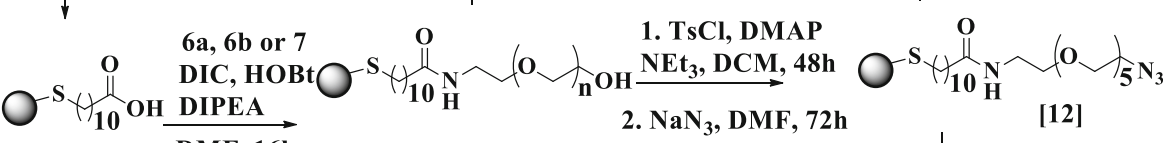

[9]

DMF, $16 \mathrm{~h}$ [10a] $(\mathrm{n}=1),[10 \mathrm{~b}](\mathrm{n}=4),[10 \mathrm{c}](\mathrm{n}=5)$

$\mathrm{SnCl}_{2}, \mathrm{PhSH}$

DIPEA

THF, 1h<smiles></smiles>

[16]

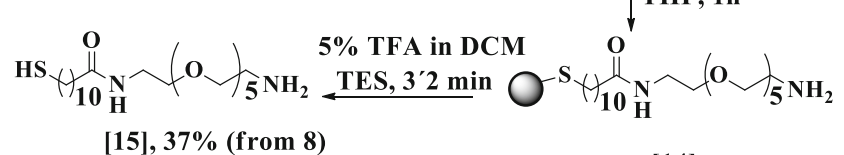

[14]

C

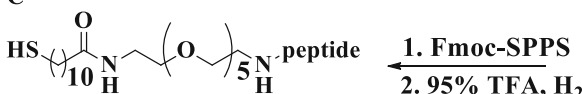

[17a] peptide $=$ KADA-NAc: $28 \%$ (from 8FES, 3 '2 min

[17b] peptide $=$ KPTA-NAc: $34 \%$ (from 8$)$

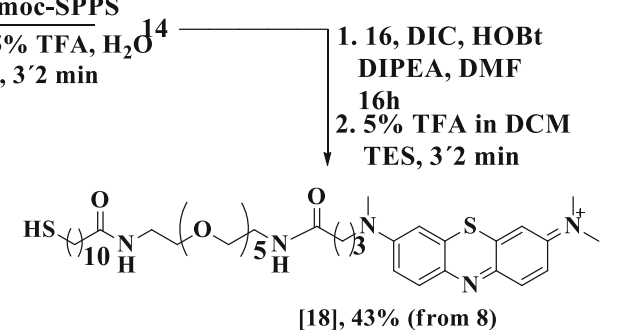

Scheme $\mathbf{4 2}$ Synthesis of LCAT-OEGs

Singh et al. [64] reported the synthesis of doped/ undoped cerium (IV) pyrophosphate compounds of different morphologies through the solution-phase synthesis in the presence of cerium (III) nitrate as a metal precursor and hydrogen peroxide as an oxidising agent. The material was studied to ascertain the phase composition and microstructure prior to synthesis. Title compounds were characterised by thermogravimetric analysis/differential thermal analysis, differential scanning calorimetry, X-ray diffraction, sintered specimen, scanning electron microscopy, electrochemical impedance spectroscopy and UV-visible spectroscopy etc. (Scheme 61, 62 and 63).

Yongchun et al. [65] found the new method for nanoparticles through microwave-assisted, heating at low temperatures, hydrothermal/solvothermal using solution-phase synthesis. The author applied different strategies to control the size, shape and dispersion of nanostructures. Here, some of the semiconductors such as $\mathrm{Bi}_{2} \mathrm{~S}_{3}$ nanorods and $\mathrm{Se}$ nanowires are prepared with diethylamine or nbutylamine as a solvent using the hydrothermal technique.

\section{Conclusion}

Combinatorial chemistry is an advanced method for the synthesis of several molecules and screening their pharmacological activity rapidly in the drug discovery process using solid- and solution-phase techniques over the past few decades. In a short period, lead identification and optimization have

$$
\mathrm{Li}_{2} \mathrm{CO}_{3}+\mathrm{Fe}_{2} \mathrm{O}_{3}+2\left(\mathrm{NH}_{4}\right)_{2} \mathrm{HPO}_{4}+3 / 2 \mathrm{C} \longrightarrow 2\left(\mathrm{LiFePO}_{4} \mathrm{C}_{0.25}\right)+3 \mathrm{H}_{2} \mathrm{O} \uparrow+4 \mathrm{NH}_{3} \uparrow+\mathrm{CO}_{2} \uparrow+\mathrm{CO} \uparrow
$$

Scheme $\mathbf{4 3}$ Synthesis of nanostructured lithium iron phosphate powders 


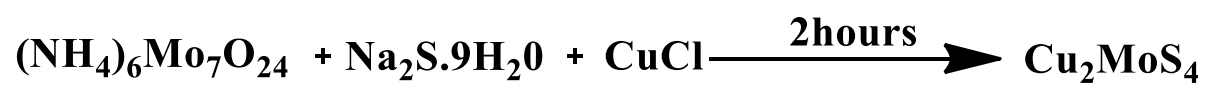

Scheme 44 Synthesis of $\mathrm{Cu}_{2} \mathrm{MoS}_{4}$ nanoparticles

$5 \mathrm{~min}$

$$
\mathrm{La}_{2} \mathrm{O}_{3}+\mathrm{ZrO}_{2} \frac{\text { of mechanoaction }}{1300^{\circ} \mathrm{C}} \rightarrow \mathrm{La}_{2} \mathrm{Zr}_{2} \mathrm{O}_{7}
$$

Scheme $\mathbf{4 5}$ Synthesis of nanocrystalline lanthanum zirconate

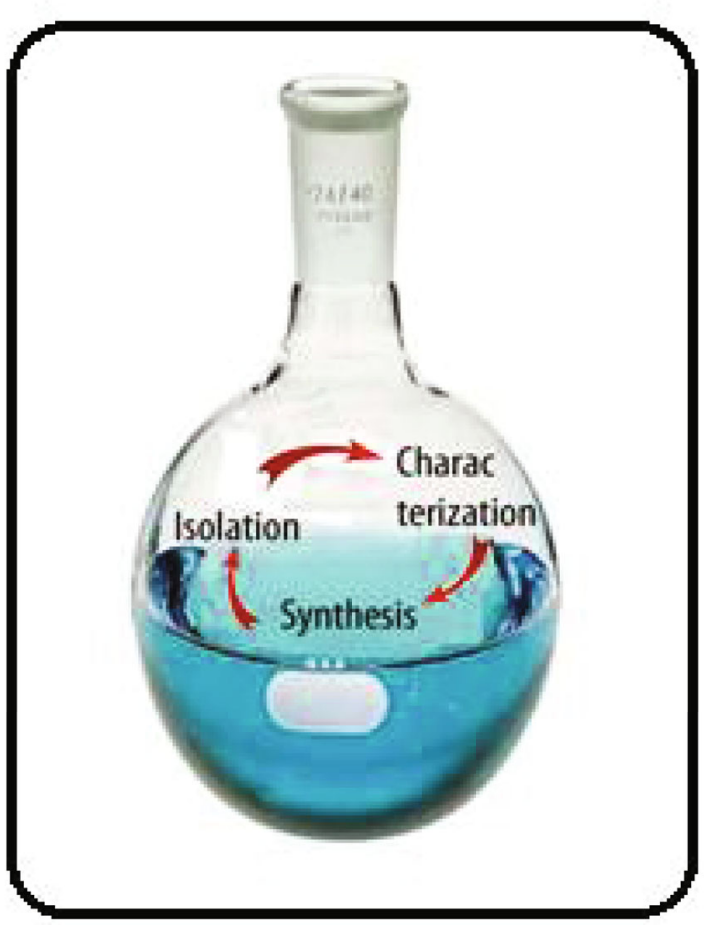

Fig. 4 Solution-phase synthesis 
Scheme 46 2-chlorobenzoyl thiourea derivatives [1-37]
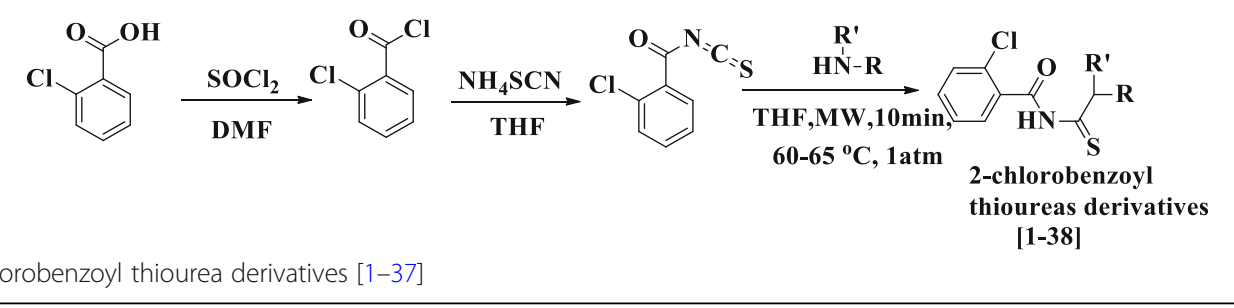

1) $\mathrm{AC}_{2} \mathrm{O}$

Pyr., rt

2) $\mathrm{HBr}(33 \mathrm{wt} \%)$

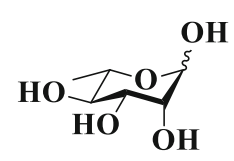

[1]

$\mathrm{Ac}_{2} \mathrm{O}$

3) Thiourea, $\mathrm{nPrBr}$

$\mathrm{MeCN}$, reflux-rt

$57 \%$ over three steps

1) $\mathrm{NaH}(60 \%), \mathrm{BnBr}$

HO Tơ

[3] $\underset{\text { 2) } \mathrm{AcOH} / \mathrm{H}_{2} \mathrm{O}}{\stackrel{\mathrm{CH}_{2} \mathrm{Cl}_{2}, 0^{\circ} \mathrm{C}-\mathrm{rt}}{\longrightarrow}}$

$8^{\circ} \mathrm{C}$

$73 \%$ over two steps

LevOH

EDC.HCl

$\mathrm{BnO}_{\mathrm{OH}}^{\mathrm{BnO}} \mathrm{SPr}$

[5]

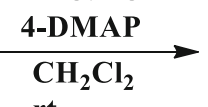

rt

$76 \%$

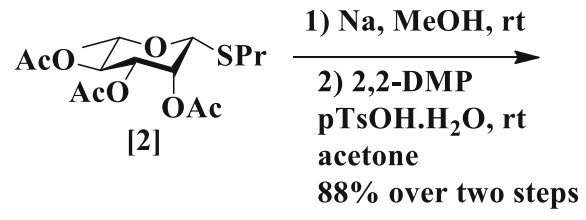

$\mathrm{Bu}_{2} \mathrm{SnO}$, toulene

reflux

then $\mathrm{Et}_{\mathbf{3}} \mathrm{N}$,

$\mathrm{BnBr}, \mathrm{CsF}$

DMF, rt

$69 \%$

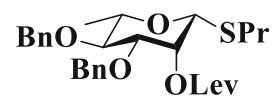

[6]

cheme 47 Donor building block synthesis

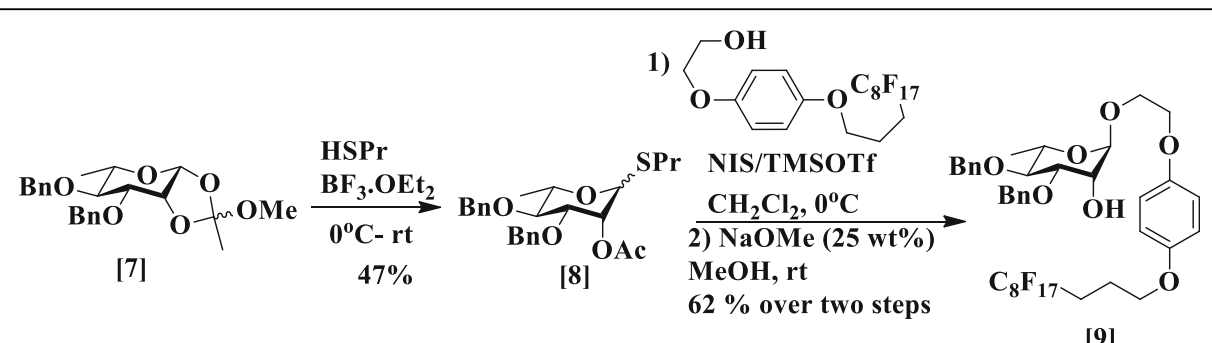

[9] 


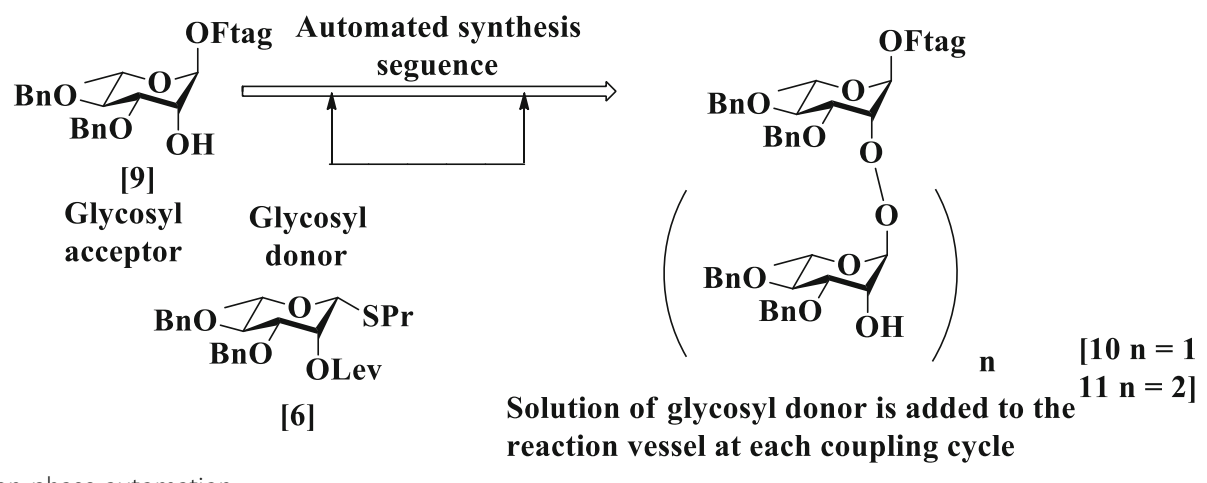

Scheme 49 Solution-phase automation

been taking place and accepted widely for the synthesis of peptides, oligonucleotides, organometallic, small proteins, non-oligomeric organic molecules, inorganic molecules and polymer chemistry. Considering all these features, many scientists employ this method for the preparation of medicinal compounds in recent days. The current review summarised a bunch of sixty-six research papers on combinatorial chemistry that witnessed the enormous growth in the past two decades. However, to the best of our knowledge, these pieces of literature completely analysed the importance of combinatorial synthesis and furnished an overview on solid-phase and solution-phase techniques as well as helped mankind by improving higher productivity at low cost, lead identification and optimization and preventing environmental pollution.

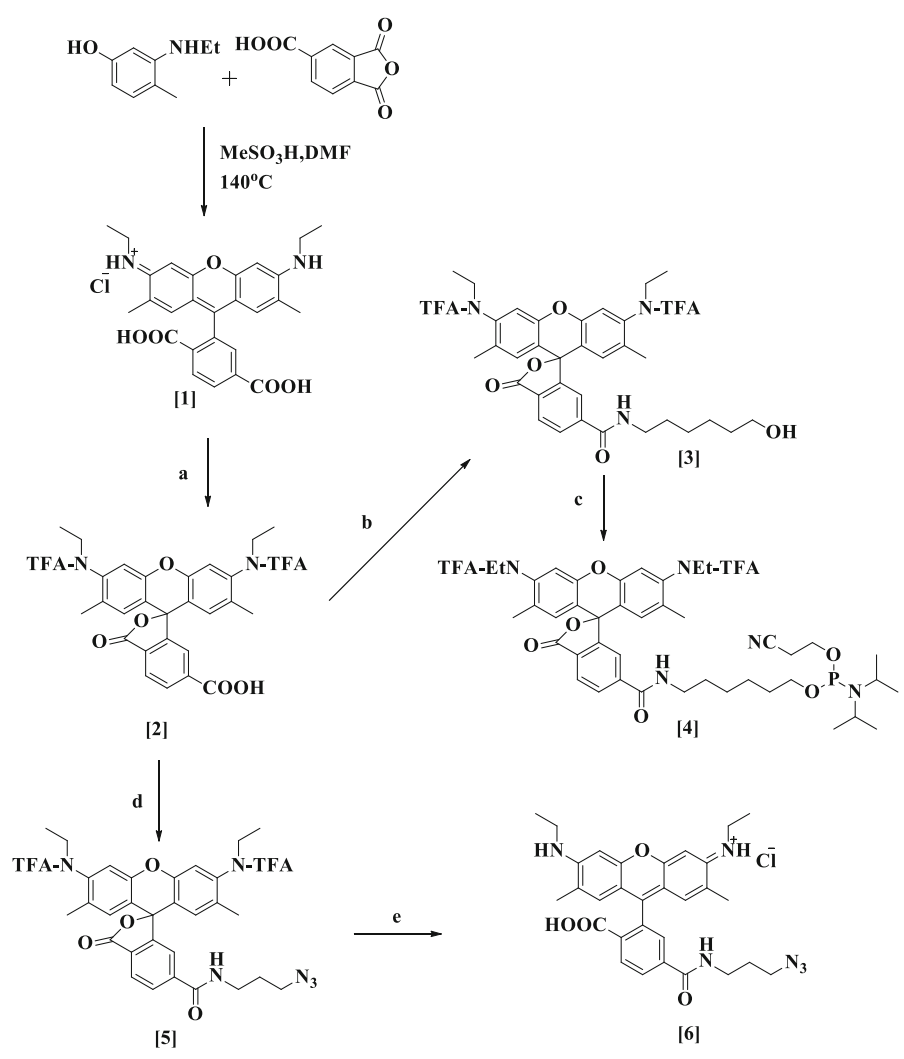

Scheme $\mathbf{5 0}$ Synthesis of R6G phosphoramidite 4 and 3-azidopropylamide [6] 

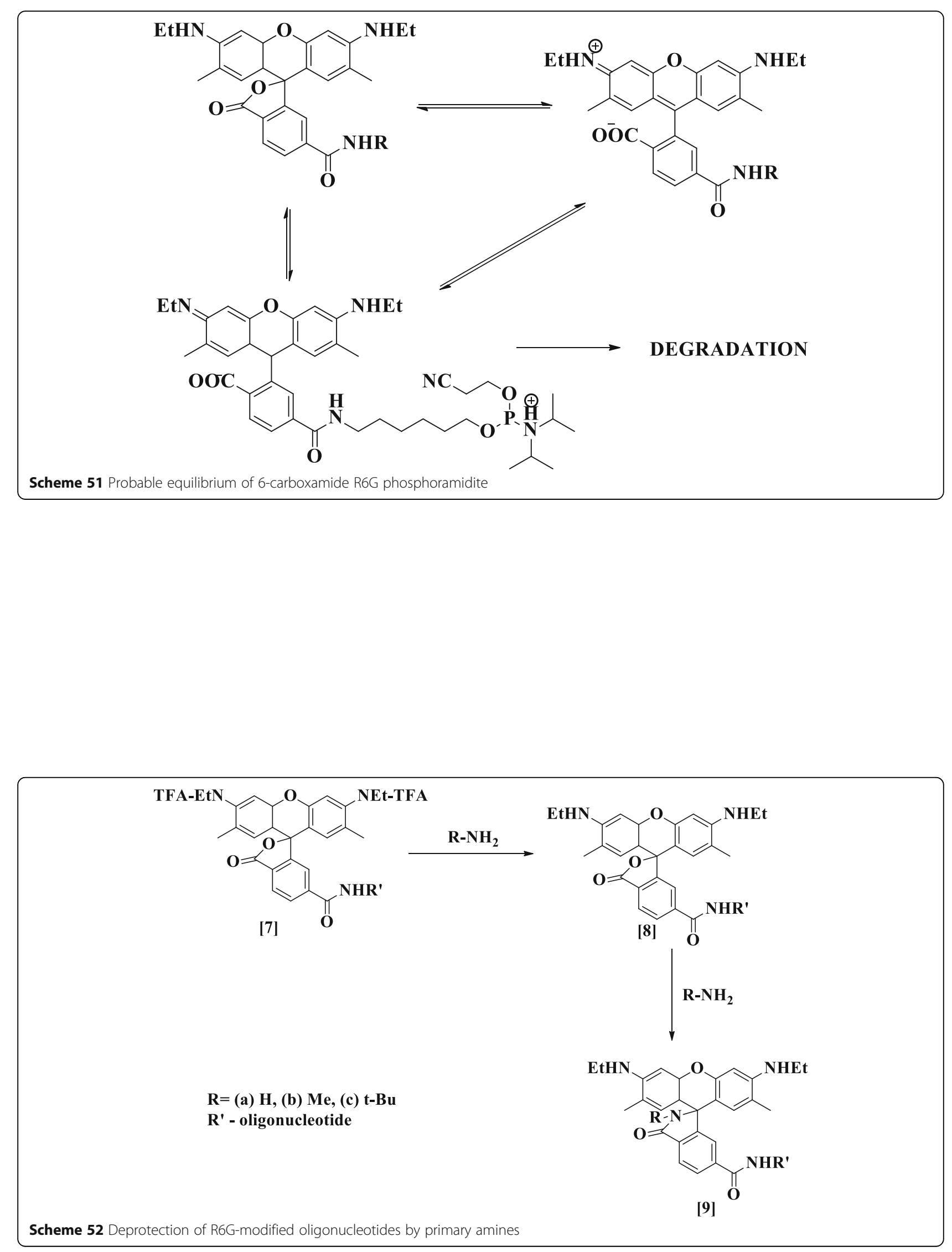

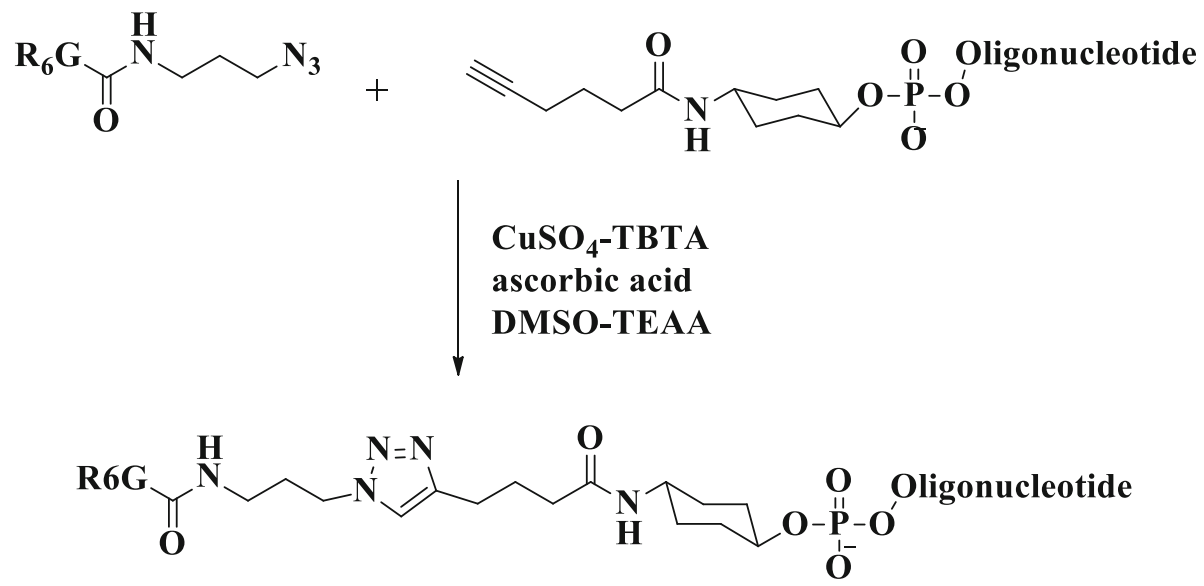

Scheme $\mathbf{5 3}$ Synthesis of R6G-labelled oligonucleotides by CuAAC

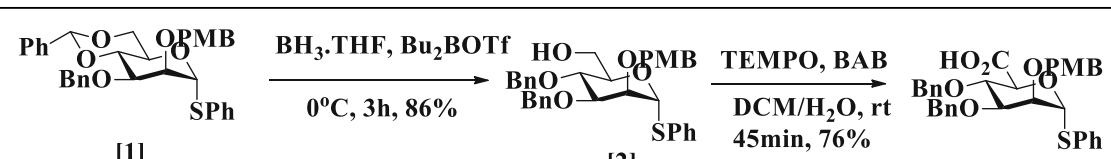

[1]

[2]

[3]

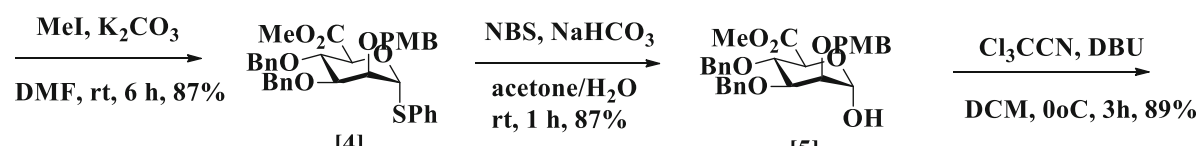

[4]

[5]

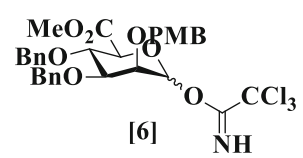

Scheme 54 Synthesis of building block 6 for the automated solution-phase synthesis of $\beta$-1,2-mannan

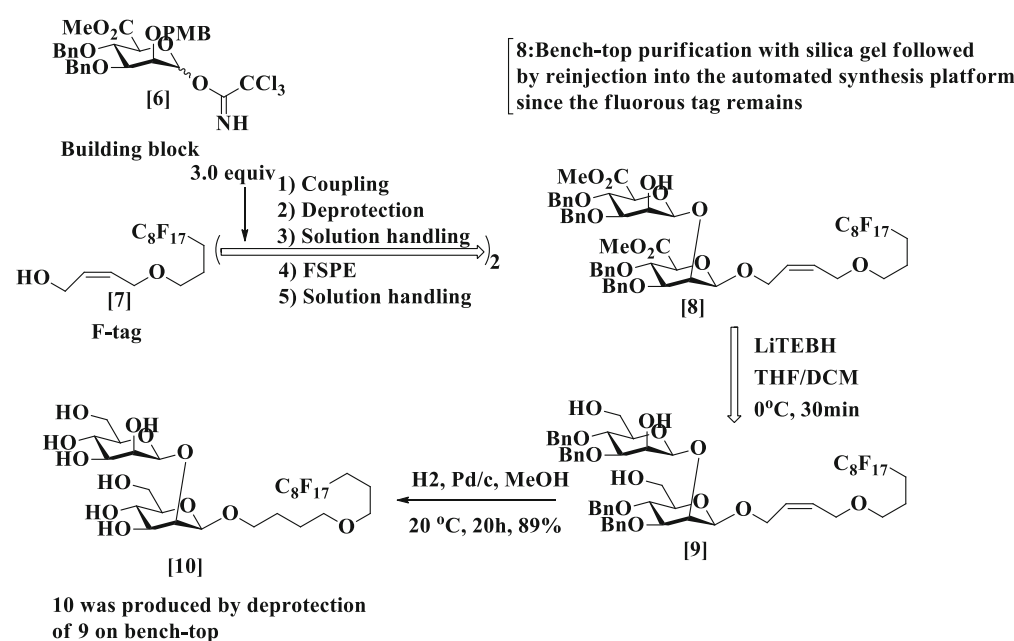

Scheme 55 Automated solution-phase synthesis of $\beta-1,2-$ mannan 10 


$$
\text { (12) Coupling }
$$

Scheme 56 Automated solution-phase synthesis of $\beta$-1,3-mannan 15

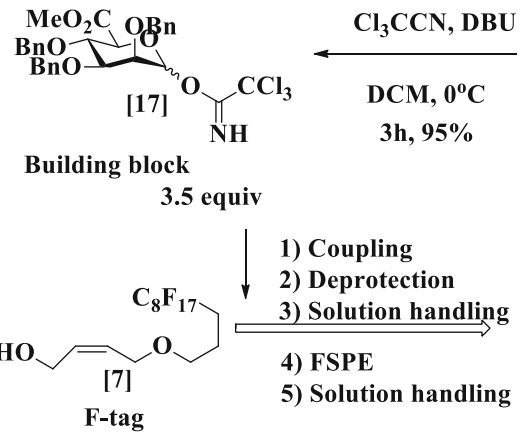

1) Coupling

2) Deprotection 3) Solution handling

4) FSPE

5) Solution handling

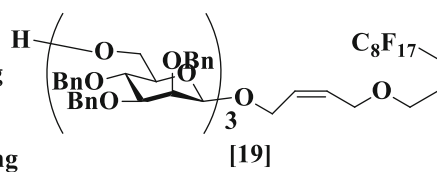

[19]

$$
\text { [16] } \mathrm{OH}
$$

18:Bench-top purification with silica gel followed] by reinjection into the automated synthesis platform since the fluorous tag remains

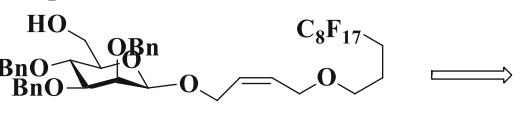

[18]

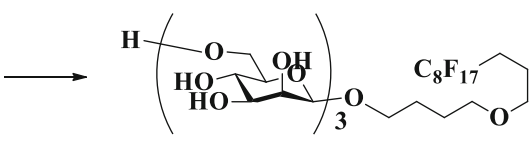

$[20]$

20 was produced by deprotection of 19 on bench-top

Scheme $\mathbf{5 7}$ Synthesis of the trichloroacetimidate building block 17 and automated solution-phase synthesis of $\beta$-1,2-mannan 20 

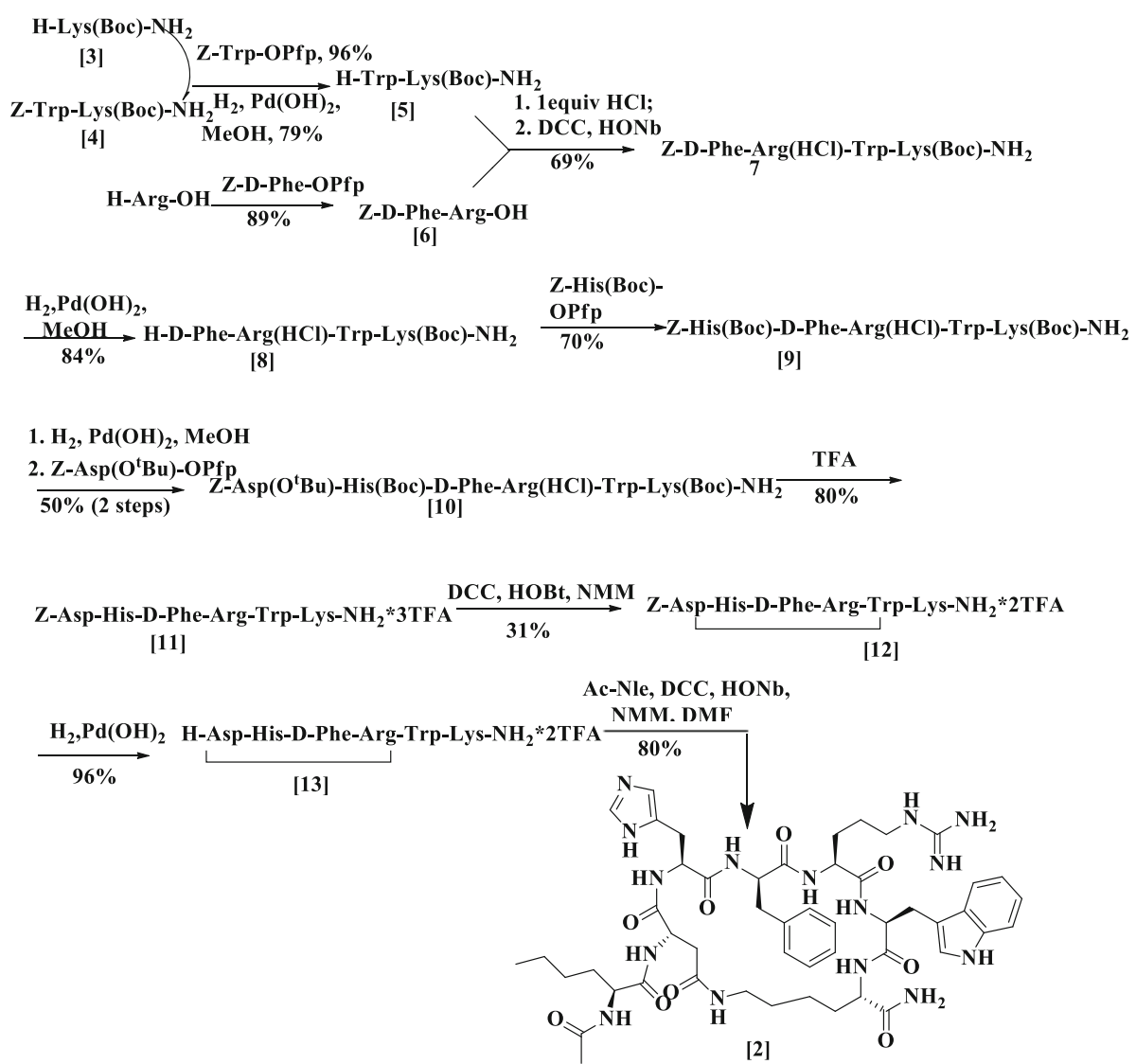

Scheme 58 Synthesis of Melanotan [11]

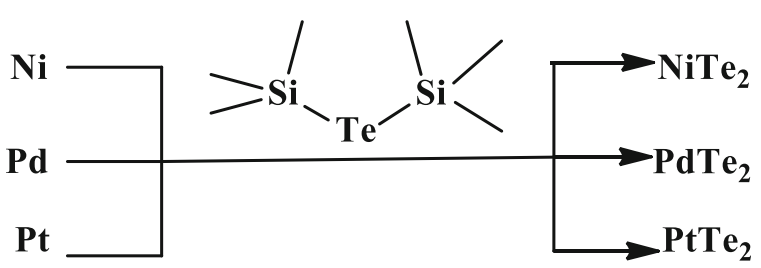

Scheme $\mathbf{5 9}$ Synthesis of nanoscale transition metal tellurides 
Cerium (III) nitrate hexahydrate (aq.)

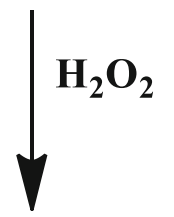

Orange-yellow ceruim (IV) solution (A)

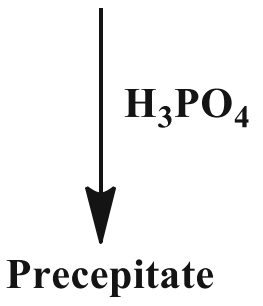

Vaporization

Calcination

\section{Mixture of phosphates of cerium}

Scheme 61 Flow chart of procedure precipitation reaction with $\mathrm{H}_{3} \mathrm{PO}_{4}$ was performed without the addition of $\mathrm{HNO}_{3}$ 

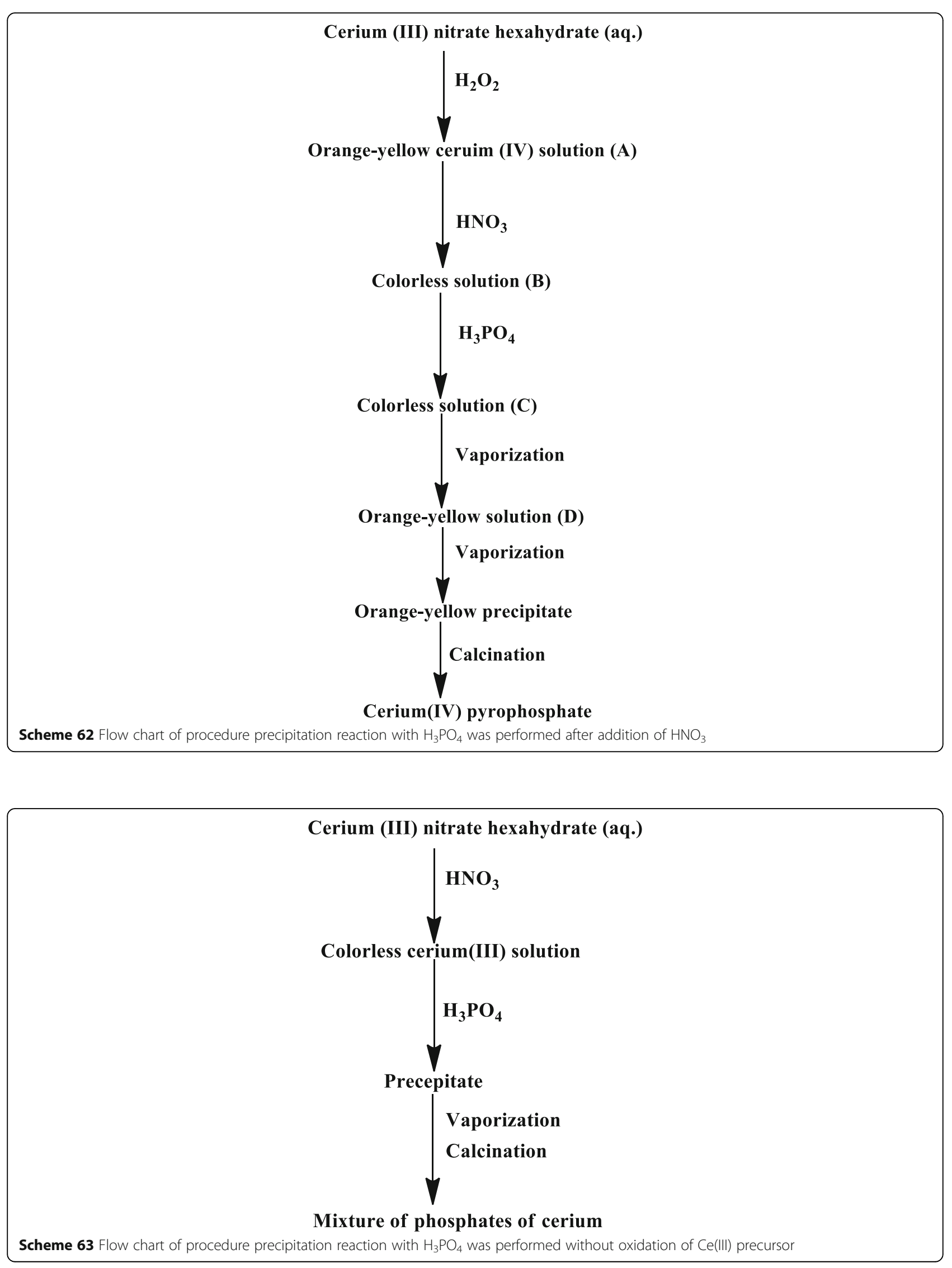


\section{Abbreviations}

FT-IR: Fourier transform infrared spectroscopy; ${ }^{1} \mathrm{H}$-NMR: Proton nuclear magnetic resonance spectroscopy; RP-HPLC: Reverse-phase highperformance liquid; ${ }^{13} \mathrm{C}-\mathrm{NMR}$ : Carbon-13 (C13) nuclear magnetic resonance; $\mathrm{LiFePO}_{4}$ : Lithium iron phosphate powders; FCNP: Fluorescent carbon nanoparticles; SPEPS: Solid-phase enzymatic synthesis; CPY: Carboxypeptidase $\mathrm{Y}_{;} \mathrm{LaZr}_{2} \mathrm{O}_{7}$ : Nanocrystalline lanthanum zirconate

\section{Acknowledgements}

All authors wish to express their gratitude to GIET School of Pharmacy,

Rajahmundry, Andhra Pradesh, India, for providing research facilities.

\section{Authors' contributions}

CG designed the study and write the whole manuscript. GK and CSS contributed the major work in drawing the schem of the mentioned artcile and assisting to write the manuscript. MDD has analysing the data and structure the manuscript in a journal format. All the author read and approved the final manuscript.

\section{Funding}

There is no external funding for this project. Authors of this manuscript contributed their money to meet the expenses.

\section{Availability of data and materials}

All the data generated and analysed during the study are included in the manuscript.

\section{Ethics approval and consent to participate}

Not applicable.

\section{Consent for publication}

Not applicable.

\section{Competing interests}

The authors declare that they have no competing interests.

\section{Author details}

'Department of pharmaceutical chemistry, GIET School of Pharmacy, NH-16, Rajahmundry, Andhra Pradesh 533296, India. ${ }^{2}$ Research lab, GIET School of Pharmacy, NH-16, Rajahmundry, Andhra Pradesh 533296, India.

Received: 16 April 2020 Accepted: 2 November 2020

Published online: 26 November 2020

\section{References}

1. Mathur S, Hoskins C (2017) Drug development: lessons from nature. Biomed Rep 6(6):612-614

2. Norman GAV (2016) Drug and devices: comparison of European and US approval process. JACC Basic Transl Sci 1(5):399-412

3. Liu R, Li X, Lam KS (2017) Combinatorial chemistry in drug discovery. Curr Opin Chem Biol 38:117-126

4. Hruby VJ, Vagner J (2006) High throughput synthesis of peptides and peptidomimetics. Chim Oggi 24(4):18-21

5. Keefe AD, Clark MA, Hupp CD, Litovchick A, Zhang Y (2015) Chemical ligation methods for the tagging of DNA-encoded chemical libraries. Curr Opin Chem Biol 26:80-88

6. Bhaskar U, Li G, Fu L, Onishi A, Suflita M, Dordick JS, Linhardt RJ (2015) Combinatorial one-pot chemoenzymatic synthesis of heparin. Carbohydr Polym 122:399-407

7. Mondal M, Hirsch AKH (2015) Dynamic combinatorial chemistry: a tool to facilitate the identification of inhibitors for protein targets. Chem Soc Rev 44:2455-2488

8. Made V, Els-Heindl S, Beck-Sickinger A (2014) Automated solid-phase peptide synthesis to obtain therapeutic peptides. Beilstein J Org Chem 10 1197-1212

9. MacConnell AB, McEnaney PJ, Cavett VJ, Paegel BM (2015) DNA-Encoded solid-phase synthesis: encoding language design and complex oligomer library synthesis. ACS Comb Sci 17:518-534

10. Isidro-Llobet A, Kenworthy MN, Mukherjee S, Kopach ME, Wegner K, Gallou F, Smith AG, Roschangar F (2019) Sustainability challenges in peptide synthesis and purification: from R\&D to production. J Org Chem 84:4615-4628
11. Weishaupt M, Eller S, Seeberger PH (2010) Solid phase synthesis of oligosaccharides. Methods Enzymol 478:463-484

12. Gao Y, Kodadek T (2013) Synthesis and screening of stereochemically diverse combinatorial libraries of peptide tertiary amides. Chem Biol 20(3): 360-369

13. Hoffmann T, Gastreich M (2019) The next level in chemical space navigation: going far beyond enumerable compound libraries. Drug Discov Today 24(5):1148-1156

14. Nakayama GR (2001) Combinatorial chemistry. Curr Opin Chem Biol 5(3): 239-240

15. Liu R, Enstrom AM, Lam KS (2003) Combinatorial peptide library methods for immunobiology research. Exp Hematol 31:11-30

16. Abdildinova A, Gong YD (2018) Current parallel solid-phase synthesis of drug-like oxadiazole and thiadiazole derivatives for combinatorial chemistry. ACS Comb Sci 20(6):309-329

17. Portilla J, Quiroga J, Abonia R, Isuasty B, Nogueras M, Cobo J, Mata EG (2008) Solution-phase and solid-phase synthesis of 1-pyrazol-3ylbenzimidazoles. Synthesis 3:387-394

18. White JB, Hausner SH, Carpenter RD, Sutcliffe J (2012) Optimization of the solid-phase synthesis of [18F] radiolabelled peptides for positron emission tomography. Appl Radiat Isot 70(12):2720-2729

19. Yamada K, Nagashima N, Hachisu M, Matsuo I, Shimizu H (2012) Efficient solid-phase synthesis of cyclic RGD peptides under controlled microwave heating. Tetrahedron Lett 53(9):1066-1070

20. Lee JH, Kim HS, Lim HS (2011) Design and facile solid-phase synthesis of conformationally constrained bicyclic peptoids. Org Lett 13(19):5012-5015

21. Wiesmayr A, Jaschke A (2011) Isolation and characterization of fluorescenceenhancing RNA tags. Bioorgan Med Chem 19(3):1041-1047

22. Mullen DG, Kyro K, Hauser M, Gustavsson M, Vegila G, Becker JM, Naider F, Distefano MD (2011) Synthesis of a-factor peptide from Saccharomyces cerevisiae and photoactive analogues via Fmoc solid-phase methodology. Bioorgan Med Chem 19(1):490-497

23. Hirose T, Kasai T, Akimoto T, Endo A, Sugawara A, Nagasawa K, Shiomi K, Omura S, Sunazuka T (2011) Solution-phase total synthesis of the hydrophilic natural product argifin using 3,4,5-tris(octadecyloxy)benzyl tag Tetrahedron 67(35):6633-6643

24. Rosenfeld A, Brehm M, Welle A, Trouillet V, Heissler S, Benz M, Levkin PA (2019) Solid-phase combinatorial synthesis using microarrays of microcompartments with light-induced on-clip cell screening. Mater Today Bio 3:100022

25. Roper KA, Lange H, Polyzos A, Berry MB, Baxendale IR, Ley SV (2011) The application of a monolithic triphenylphosphine reagent for conducting appel reactions in flow microreactors. Beilstein J Org Chem 7:1648-1655

26. Pino MS, Rodriguez-Jasso RM, Michelin M, Flores-Gallegos AC, MoralesRodriguez R, Ja T, Ruiz HA (2018) Bioreactor design for enzymatic hydrolysis of biomass under the biorefinery concept. Chem Eng 347:119-136

27. Altava B, Burguete MI, Garcia-Verdugo E, Luis SV (2018) Chiral catalysts immobilized on achiral polymers: effect of the polymer support on the performance of the catalyst. Chem Soc Rev 47:2722-2771

28. Gao Y, Kodadek T (2014) Split-and-pool synthesis and characterization of peptide tertiary amide library. J Vis Exp 88:51299

29. Townsend JB, Shaheen F, Liu R, Lam KS (2010) Jeffamine derivatized tentaGel beads and PDMS microbead cassettes for ultra-high throughput in situ releasable solution-phase cell-based screening of OBOC combinatorial small-molecule libraries. J Comb Chem 12(5):700-712

30. Prior AM, Hori T, Fishman A, Sun D (2018) Recent reports of solid-phase cyclohexapeptide synthesis and applications. Molecules 23:1475

31. Magtaan JK, Devocelle M, Kelleher F (2019) Regeneration of aged DMF for use in solid-phase peptide synthesis. J Pept Sci 25:e3139

32. Batra S, Srinivasan T, Rastogi SK, Kundu B, Patra A, Bhaduri AP, Dixit M (2002) Combinatorial synthesis and biological evaluation of isoxazole-based libraries as antithrombotic agents. Bioorg Med Chem Lett 12:1905-1908

33. Murru S, Nefzi A (2014) Combinatorial synthesis of oxazol-thiazole Bisheterocyclic compounds. Combinatorial synthesis of oxazol-thiazole Bisheterocyclic compounds. ACS Comb Sci 16(1):39-45

34. Drew DL, Ahammad T, Serafin A, Butcher BJ, Clowes KR, Drake Z, Sahu ID, McCarrick RM, Lorigan GA (2019) Solid-phase synthesis and spectroscopic characterization of the active and inactive forms of bacteriophage S21 pinholin protein. Anal Biochem 567:14-20

35. Sun S, Chen J, Zhao R, Bierer D, Wang J, Fang G, Li Y (2019) Efficient synthesis of a side-chain extended diaminodiacid for solid-phase synthesis of peptide disulfide bond mimics. Tetrahedron Lett 60:1197-1201 
36. Blanc A, Dietrich DJ, Perrin DM (2018) Solid-phase synthesis of amanitin derivatives and preliminary evaluation of cellular uptake and toxicity. J Pept Sci 111:e24050

37. Rajavenkatesh K, Santhoshkumar S, Purnasai K, Thennarasu S (2019) A facile method for monitoring solid-phase peptide synthesis and for $\mathrm{N}$-terminal modification of peptides: synthesis of short peptides for imaging specific cells. J Chem Sci 131:108

38. Liu J, Cheng R, Rozovsky S (2018) Synthesis and semisynthesis of selenopeptides and selenoproteins. Curr Opin Chem Biol 46:41-47

39. Monaim SAHA, Acosta GA, Royo M, El-Faham A, Torre BG, Albericio F (2018) Solid-phase synthesis of homodetic cyclic peptides form Fmoc-MeDbz-resin. Tetrahedron Lett 59:1779-1782

40. Na-Choi I, Oliveras A, Feliu L, Planas M (2019) Solid-phase synthesis of biaryl bicyclic peptides containing a 3-aryltyrosine or a 4-arylphenylanine moiety. Beilstein J Org Chem 15:761-768

41. Shan Y, Wang M, Qi W, Su R, He Z (2018) Solid-phase enzymatic peptide synthesis to produce an antioxidant dipeptide. Trans Tianjin Univ 25:276-282

42. Ng-Choi I, Oliveras A, Feliu L, Planas M (2020) Solid-phase synthesis of biaryl cyclic peptides containing a histidine-phenylalanine linkage. Int J Pept Res Ther 26:695-707

43. Li Y, Wu M, Chang Q, Zhao X (2019) Solid-phase synthesis of cyclic octapeptide phakellistatin 15. Chem Nat Compd 55(3):520-523

44. Jad YE, Acosta GA, Govender T, Kruger HG, El-Faham A, Torre BG, Albericio F (2016) Green solid-phase peptide synthesis 2.2-methyltetrahydrofuran and ethyl acetate for solid-phase peptide synthesis under green conditions. ACS Sustain Chem Eng 4:6809-6814

45. Meschaninova MI, Novopashina DS, Semikolenova OA, Silnikov VN, Venyaminova AG (2019) Novel convenient approach to the solid-phase synthesis of oligonucleotide conjugates. Molecules 24:4266

46. Yang S, Chen X, Liu S, Wang F, Ouyang G (2018) Microwave-assisted solidphase synthesis of highly fluorescent carbon nanoparticles and its application in intracellular Ph sensing. Talanta 186:80-87

47. Hara Rl, Yaoita A, Takeda K, Ueki H, Ishii A, Imoto H, Kobayashi S, Sano M, Noro M, Sato K, Wada T (2018) Solid-phase synthesis of fluorinated analogues of glycosyl 1-phosphate repeating structures from Leishmania using the phosphoramidite method. ChemistryOpen 7(6):439-446

48. Kines C, Hammerbacher K, Bonaterra GA, Kinscherf R, Rosemeyer H (2016) Novel nucleolipids of pyrimidine $\beta$-D-Ribonucleosides: combinatorial synthesis, spectroscopic characterization and cytostatic/cytotoxic activities. Chem Biodivers 13:160-180

49. Murray J, Nowak D, Pukenas L, Azhar R, Guilorit M, Walti C, Critchley K, Johnson S, Bon RS (2014) Solid-phase synthesis of functionalised SAMforming alkanethiol-oligoethyleneglycols. J Mater Chem B 2:3741-3744

50. Kerbel BM, Katsnelson LM, Falkovich W (2018) Continuous solid-phase synthesis of nanostructured lithium iron phosphate powders in air. Ceram Int 44:8397-8402

51. Li S, Ma R, Wang C (2018) Solid-phase synthesis of $\mathrm{Cu}_{2} \mathrm{MoS}_{4}$ nanoparticles for degradation of methyl blue under a halogen-tungsten lamp. Int J Min Met Mater 25(3):310-314

52. Kalinkin AM, Usoltsev AV, Kalinkina EV, Nevedomskii VN, Zalkind OF (2017) Solid-phase synthesis of nanocrystalline lanthanum zirconate using mechanical activation. Russ J Gen Chem 87(10):2258-2264

53. Shi S, Zhu S, Gerritz SW, Esposito K, Padmanabha R, Li W, Herbst JJ, Wong H, Shu YZ, Lam KS, Sofia MJ (2005) Solid-phase synthesis and anti-infective activity of a combinatorial library based on the natural product anisomycin. Bioorg Med Chem Lett 15:4151-4154

54. Kim SJ, McAlpine SR (2013) Solid-phase versus solution-phase synthesis of heterocyclic macrocycles. Molecules 18:1111-1121

55. Dawson SJ, Hu X, Claerhout S, Huc I (2016) Solid-phase synthesis of helically folded aromatic oligoamides. Method Enzymol 580:279-301

56. Wu J, An G, Lin S, Xie J, Zhou W, Sun H, Pan Y, Li G (2014) Solution-phasepeptide synthesis via the group-assisted purification (GAP) chemistry without using chromatography and recrystallization. Chem Commun 50(10): 1259-1261

57. Khana MR, Zaib S, Rauf MK, Ebihara M, Badshah A, Zahid M, Nadeem MA, lqbal J (2018) Solution-phase microwave assisted parallel synthesis, biological evaluation and in silico docking studies of 2-chlorobenzoyl thioureas derivatives. J Mol Struct 1164:354-362

58. Kohout VR, Pirinelli AL, Pohl NLB (2019) Acid-mediated N-iodosuccinimidebased thioglycoside activation for the automated solution-phase synthesis of a-1,2-linked-rhamnopyranosides. Pure Appl Chem 91(7):1243-1255
59. Skoblov AY, Vichuzhanin MV, Farzan VM, Veselova OA, Konovalova TA, Podkolzin AT, Shipulin GA, Zatsepin TS (2015) Solid- and solution-phase synthesis and application of R6G dual-labeled oligonucleotide probes. Bioorg Med Chem 23(20):6749-6756

60. Tang S, Pohl NLB (2016) Automated fluorous-assisted solution-phase synthesis of $\beta-1,2-, 1,3-$ and 1,6-mannan oligomers. Carbohydr Res 430:08-15

61. Ryakhovsky W, Khachiyan GA, Kosovova NF, Isamiddinova EF, Ivanov A (2008) The first preparative solution-phase synthesis of Melanotan II. Beilstein J Org Chem 4:39

62. Fenton JL, Fagan AM, Schaak RE (2019) General solution-phase synthesis of nanoscale transition metal tellurides using metal nanoparticle reagents. Eur J Inorg Chem 30:3490-3493

63. Kambe T, Haruta N, Imaoka T, Yamamoto K (2017) Solution-phase synthesis of $\mathrm{Al}_{13^{-}}$using a dendrimer template. Nat Commun 8:2046

64. Singh B, Devi N, Mathur L, Song S, Srivastava AK, Singh RK, Ashiq M, Mondal DP (2019) A new solution-phase synthesis of cerium(IV) pyrophosphate compounds of different morphologies using cerium(III) precursor. J Alloys Compd 793:686-694

65. YongChun ZHU, YiTai Q (2009) Solution-phase synthesis of nanomaterials at low temperature. Sci China Phys Mech 52(1):13-20

\section{Publisher's Note}

Springer Nature remains neutral with regard to jurisdictional claims in published maps and institutional affiliations.

\section{Submit your manuscript to a SpringerOpen ${ }^{\circ}$ journal and benefit from:}

- Convenient online submission

- Rigorous peer review

- Open access: articles freely available online

High visibility within the field

- Retaining the copyright to your article

Submit your next manuscript at $\boldsymbol{\nabla}$ springeropen.com 